\title{
Diets enriched in fish and rapeseed oils, carnosic acid, and different chemical forms of selenium affect fatty acid profile in the periintestinal fat and indices of nutritional properties of selected tissues of lambs
}

\author{
Małgorzata Białek, Marian Czauderna and Kamil Zaworski \\ The Kielanowski Institute of Animal Physiology and Nutrition, Polish Academy of Sciences, 05-110 Jabłonna, Poland \\ e-mail: m.czauderna@ifzz.pl
}

\begin{abstract}
The aim of our study was to investigate the impact of carnosic acid (CA), selenate ("'Se) or selenized yeast ('Se) on concentrations of fatty acids (FA), tocopherols, cholesterol and malondialdehyde in the periintestinal fat (PIF) and muscles of lambs. Male lambs were fed the control diet containing rapeseed (RO) and fish (FO) oils, the CA diet containing RO, FO and CA, the ${ }^{\mathrm{Y} S e}$-CA diet with RO, FO, CA and ${ }^{\mathrm{Y}} \mathrm{Se}$, and the ${ }^{\mathrm{V}} \mathrm{Se}-\mathrm{CA}$ diet with RO, FO, CA and ${ }^{\mathrm{V}} \mathrm{Se}$. The experimental diets with CA, irrespective of the presence of ${ }^{Y} S e$ or ${ }^{V} \mathrm{~S} S$, decreased sums of saturated FA (SFA) and the thrombogenic SFA in the PIF compared to the control. The experimental diets increased the $\Delta 9$-desaturation capacity in the PIF compared to the control. The experimental diets with 'Se or VISe reduced sums of long-chain polyunsaturated FA in the PIF compared to the control and CA diets. The PIF and muscles of lambs fed the VISe-CA diet were characterised by the highest hypocholesterolemic/hypercholesterolemic-FA ratio, and lower modified atherogenic index compared to the control.
\end{abstract}

Key words: ovine periintestinal fat, muscles, tocopherols, cholesterol, oxidative stress, modified atherogenic index

\section{Introduction}

The oxidation of polyunsaturated fatty acids (PUFA), cholesterol and proteins in tissues is one of the most prevalent modifications caused by reactive oxygen and nitrogen species (ROS and RNS) in animal organisms (Saheem et al. 2017). Numerous studies have indicated that ruminants' tissues are susceptible to oxidation of lipid unsaturated fatty acids (UFA), sulphur-amino acids in proteins or cholesterol in cell membranes (Krajewska-Bienias et al. 2017, Morán et al. 2017, Przybylski et al. 2017). Dietary antioxidants (like seleno-compounds, polyphenols, carotenoids, lycopene or tocopherols) may prevent or delay some types of oxidative damage in tissues of animals and humans (Choe and Min 2009, Rozbicka-Wieczorek et al. 2014, El-Ramady et al. 2015, Gargiulo et al. 2017). In fact, studies have shown that selenium (Se) exerts its antioxidative properties through Se-proteins/enzymes of which there may be more than 35 in mammals (Edens and Sefton 2016, Collins 2017). Recent studies have shown that $\mathrm{Se}$ is not only an essential part of antioxidants but also a regulator of gene expression (Juszczuk-Kubiak et al. 2016, Zhao et al. 2016). For instance, Se supplementation promotes higher levels of the gene expression of the lipoprotein lipase and apolipoprotein E, particularly in skeletal muscle and possibly in fatty acid utilisation and triacylglyceride metabolism; as a consequence, dietary Se alters lipid metabolism and protein synthesis in the tissues of mammals. Moreover, Se-enzymes suppress pro-inflammatory cell metabolisms by reducing oxidative degradation in intracellular fluid; therefore, Se-compounds have been found to improve immunity in mammals (Raman 2000, El-Ramady et al. 2015). Endogenous Se is present in the tissues and fluids of animals and humans mostly as Se-cysteine (Se-Cys), which is the crucial functional site of 35 Se-proteins/enzymes (like thioredoxin reductases, isozymes of the glutathione-peroxidase family or iodothyronine deiodinases) or Se-methionine (SeMet), which can be bound non-specifically to Se-Met-proteins (Collins 2017). It is worth stressing that organic chemical forms of Se (like selenized yeast) are more efficiently incorporated in rumen microbiota and tissues of ruminants compared to selenate ( ${ }^{\mathrm{V}} \mathrm{S} \mathrm{S}$ ) or selenite ('vSe) (Navarro-Alarcon and Cabrera-Vique 2008, Čobanová et al. 2017, Czauderna et al. 2018). Compared to VISe, 'Ve efficiently reacts with dietary components and metabolites of ruminal microbiota (especially those with thiol groups and R-S-S-R', etc. (Czauderna and Samochocka 1981), as well as IV $\mathrm{Se}$ is directly reduced to elemental Se ( $\left.{ }^{\circ} \mathrm{Se}\right)$ by ruminal microorganisms. Unfortunately, ${ }^{\circ} \mathrm{Se}$ is unreactive in the anaerobic ruminal environment (Romero-Pérez et al. 2010). Similarly, Se absorption in mammals' tissues is

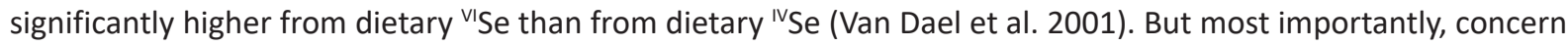
has been raised about the potential pro-oxidative properties of ${ }^{\text {IV }} \mathrm{Se}$ and its lower stability in comparison with VISe when added to diets (Van Dael et al. 2001). 


\section{AGRICULTURAL AND FOOD SCIENCE}

M. Białek et al. (2020) 29: 405-419

Recent studies have indicated that inorganic and organic Se-compounds affect microbial populations and microorganism activity (Ošt'ádalová 2012, Kišidayová et al. 2014, Čobanová et al. 2017), as well as fatty acid (FA) metabolism (like enzymatic isomerisation and biohydrogenation of UFA) in the rumen of ruminants or in in vitro incubated ruminal fluids (Czauderna et al. 2012a, 2012b, 2014, 2015, 2018, Miltko et al. 2016, Rozbicka-Wieczorek et al. 2016a, 2016b, 2016c, Białek et al. 2020). Our previous studies have indicated that dietary carnosic acid (CA), selenized yeast ('Se) or V'Se affect the concentrations of FA, total cholesterol (TCh), tocopherols and malondialdehyde (MDA, the marker of PUFA per-oxidation) in the liver, brain, muscles, blood and subcutaneous fat of lambs (Czauderna et al. 2009b, 2011, 2012a, 2012b, Rozbicka-Wieczorek et al. 2016b, 2016c). Moreover, recent studies have shown that CA (a catecholic diterpene) is used as an antioxidant and preservative in foods of animal origin (Rozbicka-Wieczorek et al. 2016b, 2016c, Morán et al. 2012a, 2012b, 2013, 2017, Ortuño et al. 2017). In fact, CA protects cellular biomolecules (like proteins, lipids, RNA and DNA) against chemical stressors, such as reactive oxygen species (ROS), paraquat (an agrochemical) or 6-hydroxydopamine. Moreover, an earlier study has reported the inhibition of pro-inflammatory mediator secretion by lipopolysaccharide-stimulated macrophages using high doses of CA (Hadad and Levy 2012). Recent studies have also shown that dietary CA can modify a rumen microorganism's profile, resulting in changes of microbiota metabolism, and the yield of biohydrogenation (BH) of UFA in the rumen (Jordán et al. 2013, Miltko et al. 2016, Rozbicka-Wieczorek et al. 2016c). For instance, CA, being rich in Rosmarinus officinalis L. leaves, decreased the ruminal abundance of protozoa, archaea, Prevotella spp., Ruminococcus albus and Clostridium aminophilum, whereas increased (though only numerically) the abundance of $R u$ minococcus flavefaciens (Cobellis et al. 2016). Interestingly, CA has the most powerful antioxidant potency among diterpenes (like carnosol, rosmanol or iso-rosmanol) in rosemary (Masuda et al. 2001). CA (a natural antioxidant) has a typical o-diphenol structure, so it is easily oxidised to carnosol, the product of the oxidative biotransformation of CA (Masuda et al. 2001, Johnson 2011, Ortuño et al. 2017). Considering the above, special attention should be paid to CA as a dietary supplement. We intend to examine the effect of one natural diterpene (not a mixture of diterpenes) with or without Se-compounds on FA and tocopherols assimilation in the periintestinal fat (PIF) of lambs. The PIF belongs to visceral fat that is stored within the abdominal cavity around a number of very important internal organs (such as the intestines, the pancreas and the liver). Storing higher amounts of visceral fat (like the PIF), however, is associated with increased risks of a number of health problems, much more so than subcutaneous fat. Considering all of the above, we hypothesise that the inclusion of CA (a lipophilic antioxidant) with/ without Se (the essential part of Se-antioxidants) in a diet with rapeseed oil (RO) and fish oil (FO) may increase the contents of tocopherols and UFA, and especially the highly unsaturated long chain PUFA (LPUFA), in the PIF and in other selected tissues of lambs. Moreover, we hypothesise that CA and Se (as 'Se or V'Se) simultaneously added to the lambs' diet enriched in FO would reduce contents of MDA, as well as increase the values of the hypocholesterolemic/hypercholesterolemic FA ratio in the PIF and other tissues. Thus, we expected that CA and 'YSe or V'Se added to a diet with RO and especially FO (rich in n-3LPUFA) would improve animal health and welfare.

Therefore, the main aim of our study is focused on animal nutrition (especially FA and tocopherols assimilation by lambs). Considering the above, we plan to investigate the effect of CA and the different chemical forms of Se (as ${ }^{\mathrm{Y} S e}$ and ${ }^{\mathrm{V}} \mathrm{Se}$ ) added to a basal diet with RO and FO (rich in n-3LPUFA) on the contents of selected FA (especially n-3LPUFA), tocopherols, TCh and MDA, as well as on values of the hypocholesterolemic/hypercholesterolemic FA ratio, and the atherogenic and thrombogenic indices in the PIF of lambs.

\section{Materials and methods}

\section{Animals, housing, experimental design, diets, management and sampling}

Lamb welfare guidelines and all handling procedures accepted by the $3^{\text {rd }}$ Local Commission of Animal Experiment Ethics at the University of Life Sciences (Warsaw, Poland) were strictly followed throughout the preliminary period and for the duration of the experiments.

Twenty-four male Corriedale lambs with an average initial body weight (BW) of $30.4 \pm 2.5 \mathrm{~kg}$ were individually penned as described in our previous publication (Czauderna et al. 2017). All experiments on the lambs and tissue collections were carried out at The Kielanowski Institute of Animal Physiology and Nutrition (Jabłonna, Poland). Briefly, during a 3-week preliminary period, the lambs were fed the basal diet (BD) (the standard concentrate-hay diet with mineral premix and vitamins; Table 1) (NRC 2007) enriched in $2 \%$ RO and $1 \%$ odourless FO (Table 2). The content of Se in the basal diet was $0.16 \mathrm{mg}$ of Se in $1 \mathrm{~kg}$ of BD. After the preliminary period, the lambs were divided into 4 groups of 6 animals; a 35-day experiment was conducted, during which animals were fed the basal diet supplemented with $2 \% \mathrm{RO}$ and $1 \% \mathrm{FO}$ (the control diet) or with $2 \% \mathrm{RO}, 1 \% \mathrm{FO}$ and antioxidant(s) (i.e. $0.1 \% \mathrm{CA}$ and/or $0.35 \mathrm{mg}$ of Se as ${ }^{\mathrm{Y}} \mathrm{Se}$ or V'Se in $1 \mathrm{~kg}$ of BD) (Table 3). About $83 \%$ of the total Se-amount of dietary ${ }^{\mathrm{Y} S e}$ is found in the chemical form of Se-Met, whereas $5 \%$ of Se is in the form of Se-Cys incorporated into the proteins of Saccharomyces cerevisiae. 
AGRICULTURAL AND FOOD SCIENCE

M. Białek et al. (2020) 29: 405-419

Table 1. Chemical composition (\%) of the concentrate-hay diet (the basal diet) with vitamins and mineral mixture ${ }^{1}$ fed to lambs

\begin{tabular}{|c|c|c|c|c|}
\hline \multirow{2}{*}{ Item } & \multirow{2}{*}{ Meadow hay ${ }^{3}$} & \multicolumn{3}{|c|}{ Concentrate $^{2}$} \\
\hline & & Barley meal & Soybean meal & Wheat starch \\
\hline Dry matter & 88.4 & 87.6 & 89.7 & 87.3 \\
\hline Crude protein & 9.50 & 9.94 & 41.81 & 0.90 \\
\hline Crude fibre & 27.29 & 2.87 & 4.34 & - \\
\hline Crude fat & 3.40 & 2.50 & 2.25 & 0.09 \\
\hline Ash & 4.85 & 1.84 & 6.16 & 0.12 \\
\hline Neutral detergent fiber & 59.17 & 18.02 & 18.81 & - \\
\hline Acid detergent fiber & 32.08 & 4.61 & 6.44 & - \\
\hline Acid detergent lignin & 4.47 & 1.14 & 1.49 & - \\
\hline
\end{tabular}

Table 2. The concentrations $\left(\mathrm{mg} \mathrm{kg}^{-1}\right)$ of the main fatty acids in the components of the lambs' diet: concentrate, meadow hay, rapeseed oil (RO) and odourless fish oil (FO) ${ }^{1}$

\begin{tabular}{|c|c|c|c|c|}
\hline Fatty acids & Concentrate & Meadow hay & RO & FO \\
\hline C8:0 & - & 83 & - & - \\
\hline C12:0 & - & 142 & - & 82 \\
\hline C14:0 & 104 & 239 & 56 & 12345 \\
\hline C15:0 & - & - & - & 477 \\
\hline c9C14:1 & - & 131 & - & 215 \\
\hline C16:0 & 3189 & 4034 & 13091 & 56947 \\
\hline c7C16:1 & - & - & - & 318 \\
\hline c9c16:1 & - & 184 & 33 & 420 \\
\hline$\sum \mathrm{C} 16: 2$ & - & - & - & 15586 \\
\hline C17:0 & - & - & - & 493 \\
\hline c9C17:1 & - & - & - & 193 \\
\hline C18:0 & 1425 & 459 & 5490 & 9452 \\
\hline c6C18:1 & - & - & 6 & 188 \\
\hline c7C18:1 & - & - & - & 842 \\
\hline c9C18:1 & 774 & 1266 & 385859 & 290592 \\
\hline c12C18:1 & - & 72 & 786 & 15834 \\
\hline c14C18:1 & - & - & - & 159 \\
\hline C18:2n-6 (LA) & 29163 & 13100 & 282394 & 114512 \\
\hline C18:3n-3 ( $\alpha$ LNA) & 1014 & 4178 & 83474 & 20968 \\
\hline c7c9c12c15C18:4 & - & - & - & 473 \\
\hline $\mathrm{C} 20: 0$ & - & 58 & 430 & - \\
\hline c11C20:1 & - & 74 & - & 24206 \\
\hline c11c14C20:2 & - & - & - & 2270 \\
\hline c8c11c14C20:3 & - & - & - & 258 \\
\hline$C 20: 4 n-6(A A)$ & - & - & - & 304 \\
\hline$c 8 c 11 c 14 c 17 c 20: 4$ & - & - & - & 607 \\
\hline$C 20: 5 n-3$ (EPA) & - & - & - & 6792 \\
\hline $\mathrm{C} 22: 0$ & - & 101 & 153 & 139 \\
\hline c11C22:1 & - & - & - & 1704 \\
\hline c13C22:1 & - & - & - & 11036 \\
\hline
\end{tabular}




\begin{tabular}{|c|c|c|c|c|}
\hline$c 13 c 16 C 22: 2$ & - & - & - & 95 \\
\hline c7c10c13c16C22:4 & - & - & - & 144 \\
\hline DPA & - & - & - & 1560 \\
\hline DHA & - & - & - & 26570 \\
\hline $\mathrm{C} 24: 0$ & - & 69 & - & - \\
\hline c15C24:1 & - & 71 & 61 & 397 \\
\hline
\end{tabular}

All details of the composition (including fatty acid compositions) of the control and experimental diets and rapeseed oil were presented in recent publications by the authors (Czauderna et al. 2017, 2018). The Se status of lambs fed the control and experimental diets has been presented in our latest papers (Czauderna et al. 2017, 2018).

The control and experimental diets were offered in two equal meals, as described previously (Czauderna et al. 2017); drinking water for animals was available ad libitum. The initial BW of lambs and body weight gain (BWG) are summarised in Table 3. After the 35-day experiment (i.e. at 0700-0800 h), all lambs were deprived of consciousness by intramuscular injections of xylazine $\left(0.2-0.4 \mathrm{mg} \mathrm{kg}^{-1}\right.$ of BW) and then slaughtered (Czauderna et al. 2017). The lambs were slaughtered in accordance with the European Union Council Regulations (EC) No 1099/2009 dated 24.09.2009 for the protection of animals at the time of slaughter in small experimental slaughterhouses. Next, tissues of PIF ( $78 \pm 9 \mathrm{~g})$, subcutaneous fat (SCF) $(92 \pm 11 \mathrm{~g})$, musculus biceps femoris (MBF) (174 $\pm 14 \mathrm{~g})$ and musculus longissimus dorsi (MLD) $(653 \pm 77 \mathrm{~g})$ were immediately removed from each lamb. All samples were homogenised straight away using a tissue homogeniser (IKA ${ }^{\circledR} T 18$ basic, Ultra-Turrax ${ }^{\circledR}$, Germany). The contents of MDA were determined in freshly homogenised PIF samples (Czauderna et al. 2011). All homogenised tissue samples were transferred into tightly sealed vessels and stored at $-32{ }^{\circ} \mathrm{C}$ for further chromatographic analyses. All samples were analysed individually. The contents of FA, TCh, MDA and tocopherols in tissue samples were expressed per $\mathrm{g}$ of fresh matter.

Table 3. The experimental scheme, the chemical composition of the control and experimental diets, the initial body weight (BW initial and the body weight gain (BWG, $\mathrm{kg}$ ) of lambs

\begin{tabular}{|c|c|c|c|}
\hline Group $^{1}$ & Additives added to the basal diet & $\mathrm{BW}_{\text {initial }} \mathrm{kg}$ & $\mathrm{BWG}^{2} \mathrm{~kg}$ \\
\hline Control group ${ }^{3}$ & $\begin{array}{l}2 \% \text { RO and } 1 \% \text { FO } \\
\text { (The control diet) }\end{array}$ & $30.6 \pm 2.4$ & $7.2 \pm 0.3^{\mathrm{ab}}$ \\
\hline CA group $^{3}$ & $\begin{array}{c}2 \% \mathrm{RO}, 1 \% \mathrm{FO} \text { and } 0.1 \% \mathrm{CA} \\
\text { (The CA diet) }\end{array}$ & $30.6 \pm 2.6$ & $6.6 \pm 0.3^{a}$ \\
\hline${ }^{\text {YSe-CA group }}{ }^{4}$ & $\begin{array}{c}2 \% \mathrm{RO}, 1 \% \mathrm{FO}, 0.1 \% \mathrm{CA} \text { and } 0.35 \mathrm{mg} \text { of } \mathrm{Se} \mathrm{as}^{\mathrm{\gamma}} \mathrm{Se} \\
\text { in } 1 \mathrm{~kg} \text { of BD } \\
\text { (The }{ }^{\mathrm{Y} S e-C A ~ d i e t)}\end{array}$ & $30.3 \pm 2.7$ & $6.6 \pm 0.3^{a}$ \\
\hline${ }^{V}$ Se-CA group ${ }^{4}$ & $\begin{array}{c}2 \% \mathrm{RO}, 1 \% \mathrm{FO}, 0.1 \% \mathrm{CA} \text { and } 0.35 \mathrm{mg} \text { of Se as }{ }^{\mathrm{V}} \mathrm{Se} \\
\text { in } 1 \mathrm{~kg} \text { of BD } \\
\text { (The }{ }^{\mathrm{V}} \mathrm{Se}-\mathrm{CA} \text { diet) }\end{array}$ & $30.3 \pm 3.0$ & $8.2 \pm 0.4^{b}$ \\
\hline
\end{tabular}

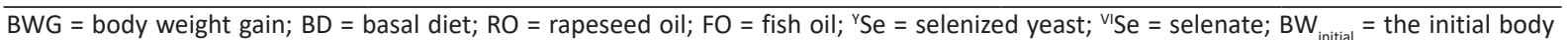
weight of lambs after the preliminary period; ${ }^{a, b}$ Different letters within a column indicate significant differences at $p<0.05 ;{ }^{1}$ For the 3 -week of preliminary period lambs were fed the diet with $2 \%$ RO and $1 \%$ FO. ${ }^{2}$ The average body weight gain (BWG, kg) of lambs fed the control or experimental diets for 35 days of the experimental period: $B W G=\left(B_{35 \text { days }}-B_{W_{\text {initial }}}\right)$, where $\mathrm{BW}_{35 \text { days }}$ - the body weight of lambs after 35 days of experiment. The average daily diet intake was $1.08 \mathrm{~kg}$ per lamb. ${ }^{3}$ The concentration of selenium in the control and CA diets was $0.16 \mathrm{mg}$ of Se in $1 \mathrm{~kg}$ of diets. ${ }^{4}$ The concentration of selenium in the ${ }^{\mathrm{Y} S e-C A}$ and ${ }^{\mathrm{V}} \mathrm{Se}-\mathrm{CA}$ diets was $0.51 \mathrm{mg}$ of Se in $1 \mathrm{~kg}$ of diets.

\section{Chemicals and analytical methods}

Commercial rapeseed oil and odourless fish oil (rich in highly unsaturated LPUFA) were purchased from Company AGSOL (Pacanów, Poland), CA was purchased from Hunan Geneham Biomedical Technology Ltd (Changsha Road, Changsha, Hunan, China), while selenized yeast (Se-Saccharomyces cerevisiae) was donated by Sel-Plex (Alltech Inc., Nicholasville, KY, USA). The vitamin and mineral premix (ID number: aPL 1405002p) was purchased from POLFAMIX OK (Grodzisk Mazowiecki, Poland).

Methanol ( $\geq 99.9 \%$ ), HPLC-acetonitrile ( $\geq 99.9 \%$ ) and $n$-hexane ( $\geq 99 \%$ ) were purchased from Lab-Scan (Dublin, Ireland). A conjugated linoleic acid (CLA) isomer mixture, a nonadecanoic acid (as the internal standard) and other 
37 fatty acid standard mixture (FAME), $\alpha$-tocopherol, $\alpha$-tocopheryl acetate, cholesterol, sorbic acid, 2,6-di-tert-butyl-pcresol, 25\% aqueous 1,5-pentanedialdehyde solution, 2,4-dinitrophenylhydrazine (containing 30\% water), 1,1,3,3-tetramethoxypropane (99\%), trichloroacetic acid and $25 \% \mathrm{BF}_{3}$ in methanol were obtained from SigmaAldrich (St Louis, MO, USA). $\mathrm{KOH}, \mathrm{NaOH}, \mathrm{Na}_{2} \mathrm{SO}_{4}$, chloroform and dichloromethane were purchased from Avantor Performance Materials (Gliwice, Poland). All other chemicals were of analytical grade.

Preparation of fatty acid methyl esters (FAME) in ovine tissues

The homogenised samples of the PIF ( 10 mg), SCF ( 10 mg) and muscles (40-50 mg) were saponified using a KOH solution according to methods described by Czauderna et al. (2007); nonadecanoic acid (as the internal standard) was added to each saponified biological sample. Then, mild base- and acid-catalysed methylations were introduced for the preparation of FAME in processed biological samples (Czauderna et al. 2007). Fatty acids (as FAME) in assayed biological samples were then determined using capillary-gas chromatography with mass spectrometry according to the methods presented by Rozbicka-Wieczorek et al. (2014). All analyses were performed on a Shimadzu GC-MS-QP2010 Plus El equipped with a BPX70 fused silica column (120 m [length] $\times 0.25 \mathrm{~mm}$ [i.d.] $\times$ $0.25 \mu \mathrm{m}$ [film thickness]) and a quadruple mass selective detector (Model $5973 \mathrm{~N}$ ). FAME identification was validated based on the electron impact ionisation spectra of FAME and compared to authentic FAME standards and the NIST 2007 reference mass spectra library (National Institute of Standard and Technology, Gaithersburg, MD, USA) (Rozbicka-Wieczorek et al. 2014).

\section{Determination of tocopherols, TCh and MDA in ovine tissues}

TCh, $\alpha$-tocopherol $(\alpha \mathrm{T}), \delta$-tocopherol $(\delta \mathrm{T}), \gamma$-tocopherol $(\gamma \mathrm{T})$ and $\alpha$-tocopheryl acetate $(\alpha \mathrm{TAC})$ were quantified in the homogenised samples of the PIF, SCF and muscles (MLD and MBF) using a liquid chromatographic system (SHIMADZU, Tokyo, Japan) according to methods described by Czauderna et al. (2009a). The liquid chromatographic instrument used consisted of an ultra-fast liquid chromatography system, incorporating two pumps, an autosampler, a CBM-20A communications bus module, a column oven, a Kinetex C18-column (2.6 $\mu \mathrm{m}$; Hydro-RP, $150 \mathrm{~mm}$ $\times 2.1 \mathrm{~mm}$; Phenomenex, Torrance, CA, USA) in conjunction with a guard column, a degasser and a photodiode array detector (Białek and Czauderna 2019).

The concentration of MDA in the PIF samples was determined after saponification followed by derivatisation according to methods described by Czauderna et al. (2011). The chromatographic separations of derivatised MDA from endogenic species of the processed PIF samples were conducted using an ultra-fast liquid chromatography system and a photodiode array detector (Czauderna et al. 2011).

Atherogenic and thrombogenic indices were calculated according to the equations given by Morán et al. (2013). The hypocholesterolemic/hypercholesterolemic fatty acid $(\mathrm{h} / \mathrm{H}-\mathrm{Ch})$ ratio was calculated using the equation given by Fernández et al. (2007).

\section{Statistical analysis}

All statistical analyses of the effects of dietary additives were carried out using the Statistica $12.5 \mathrm{PL}$ software package (StatSoft Inc., Tulsa, OK, USA). Differences were considered significant at $p<0.05$. The obtained results are shown as means and SEM (standard error of mean). The influence of dietary modifications on the contents of analytes in all biological samples for variables with normal distribution was tested with one-way ANOVA and the post-hoc Honestly Significant Difference (HSD) Tukey test. For variables without normal distribution, the results were tested with Kruskal-Wallis, which is a non-parametric equivalent of one-way ANOVA, with a post-hoc multiple comparison test.

\section{Results \\ Concentrations of selected saturated fatty acids (SFA) in the PIF of lambs}

Experimental data reflecting the contents of SFA in the PIF of lambs fed the experimental diets are summarised in Table 4. We found that the diets enriched in CA, irrespective of the presence of 'Se or VISe, resulted in a decrease in the contents of C8:0, C15:0, C17:0, C18:0, C20:0, C22:0 and the sum of thrombogenic SFA (T-SFA) in the PIF compared to the control diet. Moreover, the CA and "Se-CA diets reduced the concentration of C16:0 in the PIF as compared to the control diet. All experimental diets reduced the content sum of SFA ( $\Sigma$ SFA) in the PIF in 


\section{AGRICULTURAL AND FOOD SCIENCE}

M. Białek et al. (2020) 29: 405-419

comparison with the control diet. Moreover, the experimental diet with CA, irrespective of the presence of ${ }^{\mathrm{Y} S e}$ or

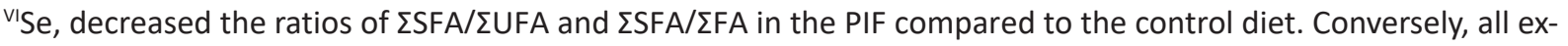
perimental diets increased the contents of C21:0 and C23:0 in the PIF compared to the control diet. The diet with ${ }^{V} \mathrm{~S} S$ caused the highest increase in the content of C21:0 in the PIF compared to the control and other experimental diets. All experimental diets had no effect on the contents of C11:0, C12:0, C13:0, C14:0, the atherogenic SFA (A-SFA) and the sum of medium-chain SFA ( $\Sigma_{\text {medium }}$ SFA) in the PIF.

The content ratio of A-SFA to the sum of FA (A-SFA/ $\angle F A)$ in the PIF of lambs fed the VISe-CA diet was lower than in the PIF of lambs fed the control, CA and ' $\mathrm{S}$ Se-CA diets. The CA and 'Se-CA diets elevated the values of the A-SFA/ $F A$ ratio in the PIF compared to the control diet. To the contrary, all experimental diets, especially the ${ }^{\mathrm{Y}} \mathrm{Se}-\mathrm{CA}$ diet, reduced the values of the T-SFA/ $\mathrm{FFA}$ ratio in the PIF in comparison with the control diet.

Table 4. The concentrations ( $\mathrm{mg} \mathrm{g}^{-1} \mathrm{PIF}$ ) of selected individual saturated fatty acids (SFA), atherogenic-SFA ${ }^{1}$ (A-SFA), thrombogenic$\mathrm{SFA}^{2}$ (T-SFA), the sums of medium-chain SFA $\left(\Sigma_{\text {medium }} \text { SFA }\right)^{3}$, all assayed SFA ( $\Sigma$ SFA $)^{4}$ and the ratios of $\sum$ SFA to the sum of PUFA ( $\Sigma$ SFA $/ \sum$ PUFA), UFA ( $\Sigma$ SFA/ $\Sigma$ UFA) and all assayed FA ( $\sum$ SFA/ $\left.\sum F A\right)$ in the periintestinal fat (PIF) of lambs

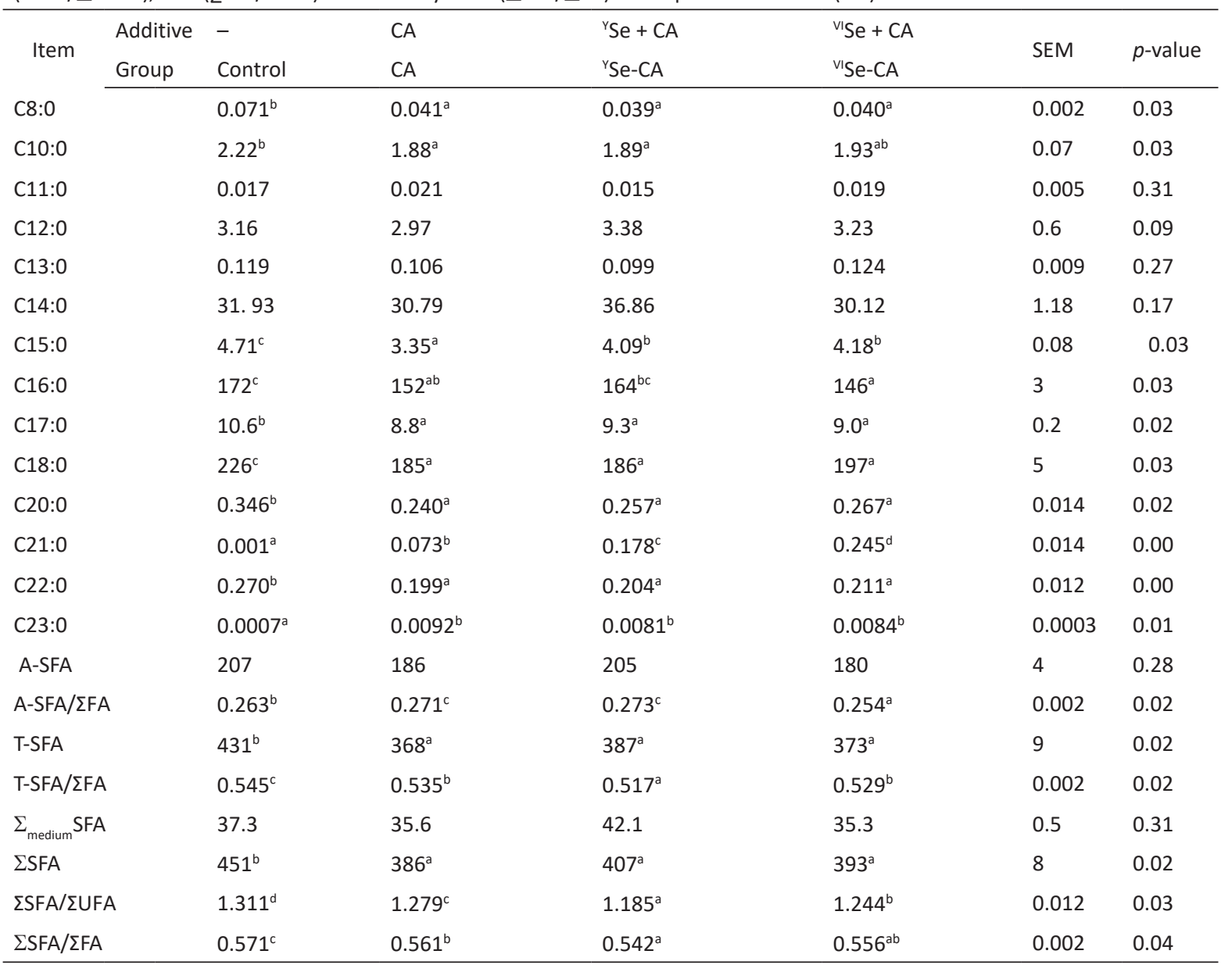

SEM = standard error of the mean; UFA = unsaturated fatty acids; PUFA = polyunsaturated fatty acids. ${ }^{\mathrm{a}, \mathrm{b}}$ Different letters within a row indicate significant differences at $p<0.05 .{ }^{1}$ The sum: C12:0, C14:0 and C16:0; ${ }^{2}$ The sum: C14:0, C16:0 and C18:0; ${ }^{3}$ The sum: C8:0, C10:0, C12:0 and C14:0; ${ }^{4}$ The sum: C8:0, C10:0, C11:0, C12:0, C13:0, C14:0, C15:0, C16:0, C17:0, C18:0, C20:0, C21:0, C22:0 and C23:0

\section{Concentrations of unsaturated fatty acids in the PIF of lambs}

The influence of the experimental diets enriched in CA with or without Se (as ${ }^{\mathrm{V} S e}$ or ${ }^{\mathrm{V}} \mathrm{Se}$ ) on the contents of monounsaturated fatty acids (MUFA) and PUFA are presented in Tables 5 and 6 . The results of our experiments demonstrated that ${ }^{V I S e}$ added to the diet with CA reduced the contents of $c 7 C 16: 1, c 9 C 16: 1, c 6 C 18: 1$ and $c 11 C 20: 1$ in comparison with the control and 'Se-CA diets (Table 5). We found that the experimental diet supplemented only with CA resulted in a decrease in the contents of $c 9$ C14:1, $c 7$ C16:1, $c 9$ C16:1, $c 6 C 18: 1$ and $c 11$ C20:1 in the PIF compared to the control diet. Conversely, no noticeable differences in the content of $t 11 \mathrm{C} 18: 1$ (TVA) and $c 9 C 18: 1$, the sum of all assayed MUFA ( MUFA) and the ratio of $\Sigma$ MUFA/ FFA were found between the control and all experimental groups of lambs. 


\section{AGRICULTURAL AND FOOD SCIENCE}

M. Białek et al. (2020) 29: 405-419

Indices of $\Delta 9$-desaturation of C18:0 ( ${ }^{\mathrm{C} 18: 1} \Delta$ 9-index) and $\Delta$ 9-desaturation of C16:0 and C18:0 ( $\Sigma \Delta$-index) were higher in the PIF of lambs fed the experimental diets than in the PIF of the control lambs. Moreover, the diet supplemented with ${ }^{Y}$ Se most efficiently elevated the ${ }^{C 18: 1} \Delta 9$-index and $\Sigma \Delta 9$-index in the PIF. Similarly, all experimental diets, particularly those supplemented with ${ }^{\mathrm{Y} S e}$ or ${ }^{\mathrm{V}} \mathrm{Se}$, increased the values of the PUFA elongase index (Elongindex) in the PIF compared to the control diet. To the contrary, all experimental diets, especially the VISe-CA diet, reduced the index values of $\Delta$ 9-desaturation of TVA ( ${ }^{\mathrm{CLA}} \Delta 9$-index) in the PIF in comparison with the control diet. The values of $\Delta 4$-desaturation ( $\triangle 4$-index) of $c 7 c 10 c 13 c 16 c 19 C 22: 5$ (DPA) were smaller in the PIF of lambs fed the experimental diets, including extra Se (as Y Se or V'Se), than in the PIF of lambs fed the control and CA diets.

Table 5. The concentrations ( $\mathrm{mg} \mathrm{g}^{-1} \mathrm{PIF}$ ) of selected individual monounsaturated fatty acids (MUFA), the concentration sum of all assayed MUFA ( $\Sigma$ MUFA) ${ }^{1}$ and index values of $\Delta$ 9-desaturases ( ${ }^{\mathrm{C} 18: 1} \Delta 9$-index ${ }^{2}, \Sigma \Delta$-index ${ }^{3}$ and ${ }^{\mathrm{CLA}} \Delta 9$-index ${ }^{4}$ ) in the periintestinal fat (PIF) of lambs

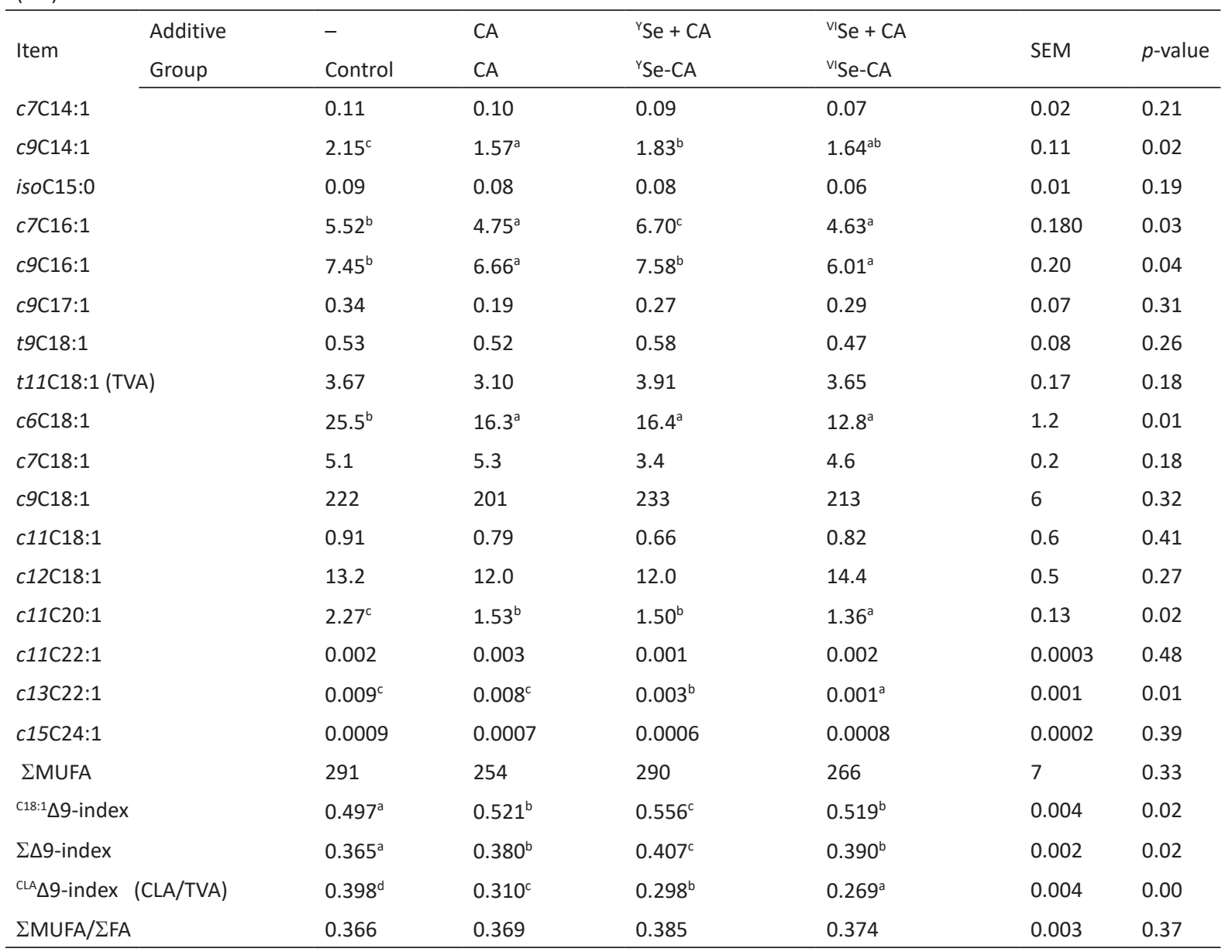

SEM = standard error of the mean; CLA = conjugated linoleic acid isomers. ${ }^{\mathrm{a}, \mathrm{b}}$ Different letters within a row indicate significant differences at $p$ <0.05. ${ }^{1}$ The sum: $c 7 C 14: 1$, c9C14:1, isoC15:1, c7C16:1, c9C16:1, c9C17:1, t9C18:1, t11C18:1, c6C18:1, c7C18:1, c9C18:1, c11C18:1, c12C18:1, c11C20:1, c11C22:1, c13C22:1 and $c 15 C 24: 1 .{ }^{2}$ c18:1 $\Delta 9$-index $=c 9 C 18: 1 /\left(c 9 C 18: 1+\right.$ C18:0). ${ }^{3} \Sigma \Delta 9$-index $=(c 9 C 16: 1+c 9 C 18: 1) /(c 9 C 16: 1+C 16: 0$ $+c 9 C 18: 1+$ C18:0). ${ }^{4 \text { CLA }} \Delta 9$-index $=c 9 t 11$ CLA/(c9t11CLA + TVA) (see Table 4).

As can be seen from the results in Table 6, all experimental diets affected the contents of PUFA in the PIF. Indeed, the contents of $c 9 t 11$ CLA, $c 11 c 14 C 20: 2$ and c5c8c11c14c17C20:5 (EPA) were smaller in the PIF of lambs fed the experimental diets than the control diet. Moreover, the experimental diets supplemented with ${ }^{\mathrm{V} S e}$ or VISe considerably reduced the contents of $c 11 c 14 C 20: 2, c 5 c 8 c 11 c 14 C 20: 4, c 5 c 8 c 11 c 14 c 17 C 20: 5$ (EPA) and $c 4 c 7 c 10 c 13 c 16 c 19 c 22: 5$ (DHA) in the PIF, in comparison with the control and CA diets. In contrast, the diets with ${ }^{\mathrm{V} S e}$ or VISe caused a strong increase in the concentration sum of $c t / t c C L A\left(\sum c t / t c C L A\right)$ in the PIFcompared with the control and CA diets.

The experimental diets, regardless of the presence of ${ }^{\mathrm{Y} S e}$ or ${ }^{\mathrm{V}} \mathrm{Se}$, had no effect on the contents of $c 9 c 12 \mathrm{C} 18: 2$ (LA), $c 6 c 9 c 12 C 18: 3$ ( $\gamma$ LNA), c6c9c12c15C18:4, c8c11c14c17C20:4, c7c10c13c16C22:4, c7c10c13c16c19C22:5 (DPA), the sums of n-6PUFA ( $\Sigma n-6 P U F A)$ and PUFA ( $\Sigma$ PUFA), and the values of the ratio of $\Sigma n-6 P U F A$ to $\Sigma n-3 P U F A(n-6 / n-3)$ in the PIF. It was found that the values of the content ratio of $\Sigma$ PUFA to $\Sigma F A$ ( $\Sigma$ PUFA/ $\Sigma F A$ ) were higher in the PIF of lambs fed the ${ }^{Y} \mathrm{Se}-\mathrm{CA}$ or VISe-CA diets than the control and CA diets. Alternatively, the diets with ${ }^{\mathrm{Y} S \mathrm{Se}}$ or VISe reduced the content sums of $n$-6LPUFA ( $\Sigma n-6$ LPUFA), n-3LPUFA ( $\Sigma n-3$ LPUFA) and LPUFA ( $\Sigma$ LPUFA) in the PIF compared to the control and CA diets. As a consequence, the experimental diets with ${ }^{\mathrm{V} S e}$ or V'Se reduced the ratio values of $\Sigma$ n-3LPUFA/ $\Sigma$ FA and $\Sigma$ LPUFA/ $\Sigma$ FA in the PIF compared to the control and CA diets. 
Table 6. The concentrations $\left(\mathrm{mg} \mathrm{g}^{-1}\right)$ of $c 9 t 11 \mathrm{CLA}$, other $c t / c t C L A$ isomers $(\Sigma c t / t c C L A)^{1}$, the sum of CLA isomers $(\Sigma C L A)^{2}$, selected individual PUFA, the sums of n-6PUFA ( $\sum$ n-6PUFA $)^{3}, n-3 P U F A\left(\sum n-3 P U F A\right)^{4}, n-6 L P U F A\left(\sum n-6 L P U F A\right)^{5}, n-3 L P U F A\left(\sum n-3 L P U F A\right)^{6}$, LPUFA ( $\sum$ LPUFA $^{7}$, all PUFA ( $\sum$ PUFA) $)^{8}$, the ratios of $\sum n-6 P U F A$ to $\sum n-3 P U F A(n-6 / n-3), \sum$ PUFA to $\sum$ SFA $\left(\sum\right.$ PUFA $/ \sum$ SFA), $\sum$ PUFA to $\Sigma F A^{9}\left(\sum\right.$ PUFA $\left./ \sum F A\right)$ and $\sum \mathrm{n}-3 L P U F A$ to $\sum F A\left(\sum n-3 L P U F A / \sum F A\right)^{10}$, and elongation and $\Delta 4$-desaturation indices in the periintestinal fat (PIF) of lambs

\begin{tabular}{|c|c|c|c|c|c|c|c|}
\hline \multirow{2}{*}{ Item } & Additive & - & $\mathrm{CA}$ & ${ }^{r} \mathrm{Se}+\mathrm{CA}$ & ${ }^{\mathrm{v}} \mathrm{Se}+\mathrm{CA}$ & \multirow[t]{2}{*}{ SEM } & \multirow[t]{2}{*}{$p$-value } \\
\hline & Group & Control & CA & ${ }^{\text {rSe-CA }}$ & ${ }^{\mathrm{v}} \mathrm{Se}-\mathrm{CA}$ & & \\
\hline \multicolumn{2}{|c|}{ c9t11CLA } & $2.55^{c}$ & $1.43^{\mathrm{a}}$ & $1.72^{\mathrm{b}}$ & $1.48^{\mathrm{a}}$ & 0.09 & 0.02 \\
\hline \multicolumn{2}{|c|}{$\Sigma c t / t c C L A$} & $0.019^{\mathrm{a}}$ & $0.021^{\mathrm{a}}$ & $0.527^{b}$ & $0.824^{c}$ & 0.20 & 0.00 \\
\hline \multicolumn{2}{|l|}{$\Sigma t t C L A$} & $0.011^{\mathrm{ab}}$ & $0.009^{a}$ & $0.013^{b}$ & $0.016^{c}$ & 0.001 & 0.03 \\
\hline \multicolumn{2}{|l|}{$\Sigma C L A$} & $2.58^{\mathrm{c}}$ & $1.46^{\mathrm{a}}$ & $2.26^{\mathrm{b}}$ & $2.32^{\mathrm{bc}}$ & 0.10 & 0.04 \\
\hline \multicolumn{2}{|c|}{ c9c12C18:2 (LA) } & 50.0 & 44.7 & 50.6 & 47.1 & 1.0 & 0.37 \\
\hline \multicolumn{2}{|c|}{ c6c9c9С18:3 ( $\gamma \mathrm{LNA})$} & 0.043 & 0.027 & 0.033 & 0.040 & 0.009 & 0.51 \\
\hline \multicolumn{2}{|c|}{$c 9 c 12 c 15 \mathrm{C} 18: 3$ ( $\alpha \mathrm{LNA})$} & $3.40^{c}$ & $3.04^{b}$ & $3.21^{\mathrm{bc}}$ & $2.69^{\mathrm{a}}$ & 0.09 & 0.02 \\
\hline \multicolumn{2}{|c|}{ c6c9c12c15C18:4 } & 0.015 & 0.011 & 0.012 & 0.009 & 0.003 & 0.18 \\
\hline \multicolumn{2}{|c|}{$c 11 c 14 C 20: 2$} & $0.200^{c}$ & $0.110^{\mathrm{b}}$ & $0.003^{\mathrm{a}}$ & $0.002^{\mathrm{a}}$ & 0.019 & 0.00 \\
\hline \multicolumn{2}{|c|}{$c 8 c 11 c 14 c 17 c 20: 4$} & 0.017 & 0.009 & 0.012 & 0.013 & 0.003 & 0.21 \\
\hline \multicolumn{2}{|c|}{$c 5 c 8 c 11 c 14 C 20: 4$ (AA) } & $0.339^{b}$ & $0.357^{b}$ & $0.219^{\mathrm{a}}$ & $0.240^{\mathrm{a}}$ & 0.017 & 0.03 \\
\hline \multicolumn{2}{|c|}{$c 5 c 8 c 11 c 14 c 17 C 20: 5$ (EPA) } & $0.130^{c}$ & $0.109^{b}$ & $0.021^{\mathrm{a}}$ & $0.012^{\mathrm{a}}$ & 0.011 & 0.02 \\
\hline \multicolumn{2}{|c|}{ c7c10c13c16C22:4 } & 0.010 & 0.013 & 0.015 & 0.017 & 0.004 & 0.32 \\
\hline \multicolumn{2}{|c|}{ c7c10c13c16c19c22:5 (DPA) } & 0.212 & 0.193 & 0.211 & 0.217 & 0.010 & 0.47 \\
\hline \multicolumn{2}{|c|}{$c 4 c 7 c 10 c 13 c 16 c 19 c 22: 5(\mathrm{DHA})$} & $0.035^{c}$ & $0.030^{c}$ & $0.001^{\mathrm{a}}$ & $0.006^{\mathrm{b}}$ & 0.003 & 0.02 \\
\hline \multicolumn{2}{|c|}{$\sum n-6 P U F A$} & 50.6 & 45.1 & 50.9 & 47.3 & 1.1 & 0.13 \\
\hline \multicolumn{2}{|c|}{$\Sigma n-3 P U F A$} & $3.65^{c}$ & $3.26^{\mathrm{b}}$ & $3.42^{\mathrm{b}}$ & $2.91^{\mathrm{a}}$ & 0.09 & 0.04 \\
\hline \multicolumn{2}{|c|}{ 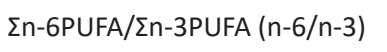 } & $14.4^{\mathrm{a}}$ & $14.5^{\mathrm{a}}$ & $15.2^{\mathrm{b}}$ & $17.0^{c}$ & 0.3 & 0.03 \\
\hline \multicolumn{2}{|c|}{$\Sigma$ n-6LPUFA } & $0.339^{b}$ & $0.357^{b}$ & $0.219^{\mathrm{a}}$ & $0.240^{\mathrm{a}}$ & 0.010 & 0.02 \\
\hline \multicolumn{2}{|c|}{$\Sigma \mathrm{n}-3$ LPUFA } & $0.376^{c}$ & $0.332^{\mathrm{b}}$ & $0.231^{\mathrm{a}}$ & $0235^{a}$ & 0.012 & 0.02 \\
\hline \multicolumn{2}{|c|}{$\Sigma n-3 L P U F A / \Sigma F A$} & $0.476^{c}$ & $0.483^{d}$ & $0.308^{\mathrm{a}}$ & $0.332^{b}$ & 0.001 & 0.03 \\
\hline \multicolumn{2}{|c|}{ ELPUFA } & $0.715^{b}$ & $0.689^{b}$ & $0.450^{\mathrm{a}}$ & $0.475^{a}$ & 0.032 & 0.04 \\
\hline \multicolumn{2}{|c|}{$\Sigma$ PUFA } & 56.8 & 49.9 & 56.5 & 52.5 & 1.1 & 0.47 \\
\hline \multicolumn{2}{|c|}{$\Sigma L \mathrm{LUFA} / \Sigma F \mathrm{FA}$} & $0.905^{c}$ & $1.003^{\mathrm{d}}$ & $0.600^{\mathrm{a}}$ & $0.671^{b}$ & 0.009 & 0.03 \\
\hline \multicolumn{2}{|c|}{$\sum$ PUFA $/ \sum$ FA } & $0.0721^{\mathrm{a}}$ & $0.0726^{a}$ & $0.0754^{c}$ & $0.0737^{b}$ & 0.0002 & 0.03 \\
\hline \multicolumn{2}{|c|}{$\Delta 4$-index ${ }^{11}$} & $0.099^{c}$ & $0.110^{d}$ & $0.003^{a}$ & $0.019^{b}$ & 0.010 & 0.01 \\
\hline \multicolumn{2}{|c|}{ EPA-Elongindex 12} & $0.620^{\mathrm{a}}$ & $0.638^{b}$ & $0.909^{c}$ & $0.948^{\mathrm{d}}$ & 0.003 & 0.02 \\
\hline
\end{tabular}

SEM = standard error of the mean. ${ }^{a, b}$ Different letters within a row indicate significant differences at $p<0.05 .{ }^{1}$ The sum of $c t / t c C L A$ isomers: cis-transCLA: 11-13, 12-14; trans-cisCLA: 7-9, 8-10, 9-11, 10-12, 11-13 and 12-14. ${ }^{2}$ The sum: c9t11CLA, ct/tcCLA isomers, ttCLA isomers (trans-trans: 7-7, 8-10, 9-11, 10-12, 11-13 and 12-14) and ccCLA isomers (cis-cis: 8-10, 9-11, 10-12 and c11-12). ${ }^{3}$ The sum: LA, c6c9c12C18:3

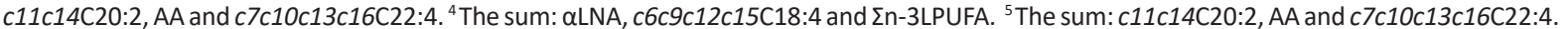

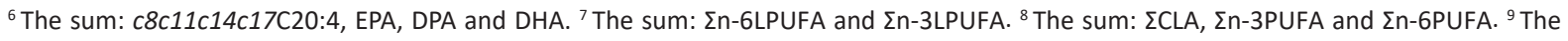
sum of all fatty acids ( $\Sigma F A)$. ${ }^{10}$ The concentration ratio of $\sum \mathrm{n}-3 \mathrm{LPUFA}\left(\mu \mathrm{g} / \mathrm{g}\right.$ PIF) to $\sum \mathrm{FA}$ (mg/g PIF). ${ }^{11} \Delta 4$-index $=c 4 c 7 c 10 c 13 c 16 c 19 \mathrm{C} 22: 6 /$

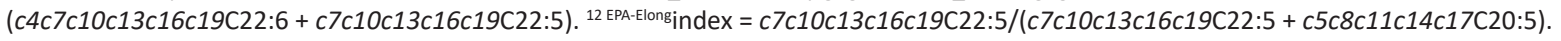

\section{Concentrations of TCh, tocopherols and MDA, and values of atherogenic, thrombogenic and hypocholesterolemic indices in selected tissues of lambs}

The experimental results reflecting the concentrations of TCh, $\delta$-tocopherol $(\delta T), \gamma$-tocopherol $(\gamma T), \alpha$-tocopherol $(\alpha T), \alpha$-tocopheryl acetate ( $\alpha \mathrm{TAc})$ and MDA are summarised in Table 7. The diets enriched in CA with or without ${ }^{V}$ 'Se reduced the content of TCh in the PIF compared to the control and 'Se-CA diets. In sheep fed the diet enriched with CA and Se (as ${ }^{\mathrm{Y} S e}$ or V'Se), the contents of $\delta \mathrm{T}$ and $\gamma \mathrm{T}$ in the PIF decreased in comparison with the control and CA diets. In contrast, the contents of $\alpha$ T and $\alpha$ TAc were higher in the PIF of lambs fed the diets enriched with ${ }^{Y} \mathrm{Se}$ or VISe than in the PIF of the control lambs. The contents of $\alpha \mathrm{T}$, and the sums of $\alpha \mathrm{T}$ and $\alpha \mathrm{TAc}(\Sigma(\alpha \mathrm{T}+\alpha \mathrm{Tac}))$ and all assayed tocopherols ( $\Sigma T s$ ) were higher in the PIF of lambs fed the ${ }^{\mathrm{V} S e-C A}$ diet than the control and VISe-CA diets. 


\section{AGRICULTURAL AND FOOD SCIENCE}

M. Białek et al. (2020) 29: 405-419

The experimental diets, especially the CA diet, reduced the content of MDA and the PUFA peroxidation index $\left(\mathrm{MDA}_{\text {index }}\right)$ in the PIF compared to the control diet. Moreover, the content of MDA was smaller in the PIF of lambs fed the diet with VISe than in the PIF of animals fed the diet with YSe. Interestingly, we found that the lowest level of MDA, and the value of MDA $_{\text {index }}$ was in the PIF of lambs fed the CA diet.

Table 7. The concentrations ( $\left.\mu \mathrm{g} \mathrm{g}^{-1} \mathrm{PIF}\right)$ of total cholesterol (TCh), tocopherols and MDA ( $\left.\mathrm{ng} \mathrm{g}^{-1} \mathrm{PIF}\right)^{1}$ and values of the PUFA peroxidation index $\left(\mathrm{MDA}_{\text {index }}\right)$ in the periintestinal fat (PIF) of lambs fed the control and experimental diets

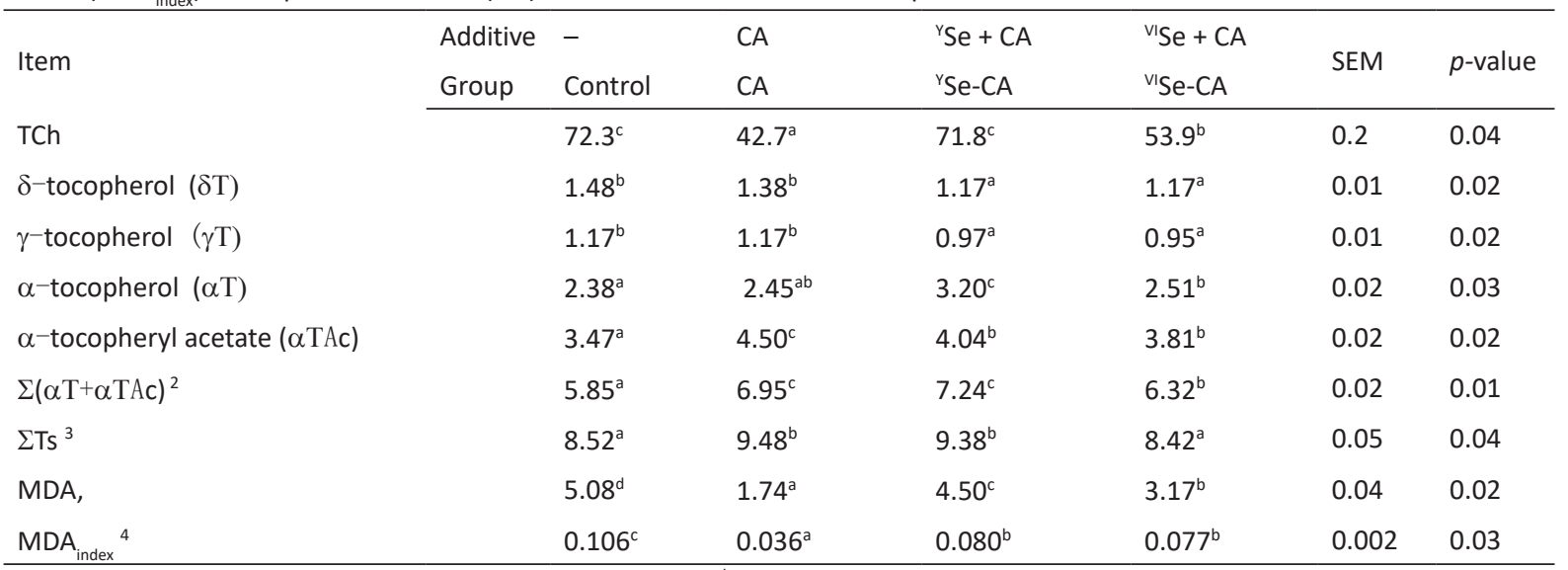

SEM = standard error of the mean; MDA = malondialdehyde; ${ }^{\mathrm{a}, \mathrm{b}}$ Different letters within a row indicate significant differences at $p<0.05$. ${ }^{1}$ Concentrations of MDA were determined immediately after the homogenization of PIF samples. ${ }^{2}$ The sum: $\alpha \mathrm{T}$ and $\alpha \mathrm{TAc} ;{ }^{3} \mathrm{The}$ sum: $\delta \mathrm{T}$,

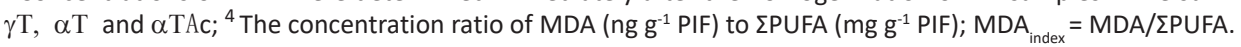

Investigation of the impact of the contents of tocopherols, A-SFA, n-6PUFA and n-3PUFA in the PIF on the atherogenic index showed that all experimental diets, especially the diet with ${ }^{\mathrm{Y} S e}$, reduced the value of our modified atherogenic index ${ }_{\text {index }} A^{\text {SFA+Toc }}$ ) in the PIF, subcutaneous fat (SCF), MLD and MBF in comparison with the control diet (Table 8).

Table 8. The $\sum$ PUFA $/ \sum$ SFA ratio $\left(\sum\right.$ PUFA $/ \sum$ SFA $)$, thrombogenic $\left({ }_{\text {index }}{ }^{\text {SFA }}\right)^{1}$ and atherogenic $\left({ }_{\text {index }} A^{\text {SFA }}\right)^{2}$ indices in the PIF of lambs. The hypo-cholesterolemic/hypercholesterolemic fatty acid $(\mathrm{h} / \mathrm{H}-\mathrm{Ch})$ ratio ${ }^{3}$ and the modified atherogenic index $\left(_{\text {index }} \mathrm{A}^{\mathrm{SFA}+\mathrm{Toc}}\right)^{4}$ in the PIF, $\mathrm{SCF}$, musculus longissimus dorsi (MLD) and musculus biceps femoris (MBF) of lambs fed the control and experimental diets

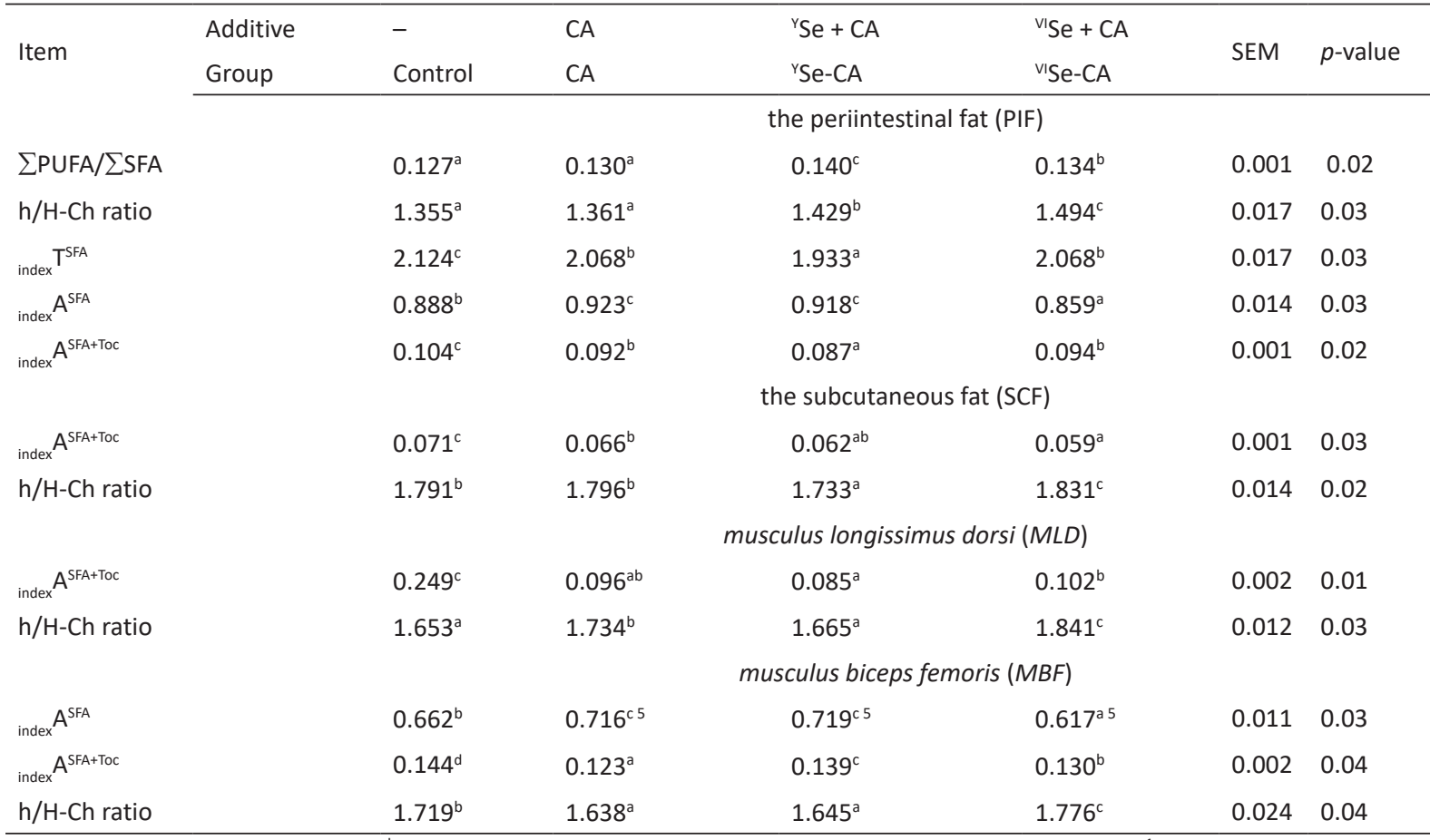

SEM = standard error of the mean. ${ }^{\mathrm{a}, \mathrm{b}}$ Different letters within a row indicate significant differences at $p<0.05 .{ }^{1}$ The thrombogenic index $=$

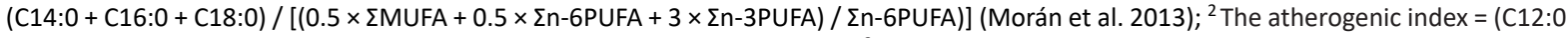

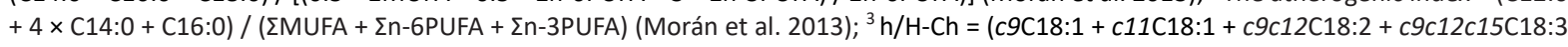
$+c 6 c 9 c 12 C 18: 3+c 8 c 11 c 14 C 20: 3+c 11 c 14 c 17 C 20: 3+c 5 c 8 c 11 c 14 C 20: 4+c 8 c 11 c 14 c 17 C 20: 4+c 5 c 8 c 11 c 14 c 17 C 20: 5+c 7 c 10 c 13 c 16 C 22: 4$ $+c 7 c 10 c 13 c 16 c 19 C 22: 5+c 4 c 7 c 10 c 13 c 16 c 19$ C22:6) / (C14:0+C16:0) (Fernández et al. 2007); ${ }^{4}$ The modified atherogenic index ( ${ }_{\text {index }} \mathrm{A}^{\text {SFA+Toc })}$ $={ }_{\text {index }} A^{\mathrm{SFA}} /\left(1.49 \times \mathrm{C}_{\alpha \mathrm{T}}+1.36 \times \mathrm{C}_{\alpha \mathrm{TAC}}+0.15 \times \mathrm{C}_{\gamma \mathrm{T}}+0.05 \times \mathrm{C}_{\delta \mathrm{T}}\right)$, where: ${ }_{\text {index }} \mathrm{A}^{\mathrm{SFA}}$ - the atherogenic index; $\mathrm{C}_{\alpha \mathrm{T}}$ - the concentration of $\alpha$-tocopherol; $C_{\alpha T A C}$ - the concentration of $\alpha$-tocopheryl acetate; $C_{\gamma T}$ - the concentration of $\gamma$-tocopherol; $C_{\delta T}$ - the concentration of $\delta$-tocopherol. Tocopherol concentrations $-\mu \mathrm{g} \mathrm{g}^{-1} .{ }^{5}$ Results were published in the previous paper (Rozbicka-Wieczorek et al. 2016b). 
Conversely, compared to the control diet, only the experimental diet with V'Se decreased the atherogenic (index $\mathrm{A}^{\mathrm{SFA}}$ ) index (Morán et al. 2013) in the PIF (Table 8), MLD (Jaworska et al. 2016) and MBF (Table 8; Rozbicka-Wieczorek et al. 2016b), whereas in the SCF, index $A^{\text {SFA }}$ was higher in lambs fed the CA and 'Se-CA diets than in the control and ${ }^{v}$ Se-CA diets (Krajewska-Bienias et al. 2017). As can be seen from the results in Table 8, all experimental diets fed to lambs decreased ${ }_{\text {index }}{ }^{\mathrm{SFA}}$ in the PIF in comparison with the control diet. It has been found that the experimental diets enriched in ${ }^{\mathrm{Y} S} \mathrm{Se}$ or ${ }^{\mathrm{V}} \mathrm{S} S \mathrm{increased}$ the $\Sigma \mathrm{PUFA} / \Sigma$ SFA ratio in the PIF, compared to the control and CA diets. The ${ }^{Y} S e-C A$ diet most effectively increased the value of the $\Sigma$ PUFA/ $\Sigma$ SFA ratio in the PIF.

As can be seen from the current results, the VISe-CA diet fed to lambs resulted in an increase in the $\mathrm{h} / \mathrm{H}$-Ch ratio in the PIF, SCF, MLD and MBF compared to the control and other experimental diets (Table 8). The addition of ${ }^{\mathrm{Y} S e}$ to the experimental diet increased $\mathrm{h} / \mathrm{H}-\mathrm{Ch}$ only in the PIF, in comparison with the control and CA diets.

\section{Discussion}

Our studies show that short-term dietary supplementation of CA and Se as VISe or ' $\mathrm{Se}$ (rich in Se-Met) can be used to modify the concentration of FA, TCh and tocopherols in the PIF, SCF and muscles of lambs without adversely influencing performance or causing physiological disorders in the liver, blood and brain (Eun et al. 2013, Rozbicka-Wieczorek et al. 2016b, 2016c, Czauderna et al. 2017, 2018, Krajewska-Bienias et al. 2017, Przybylski et al. 2017, Białek et al. 2018). Se-compounds are metabolised to intermediates and then utilised for the biosynthesis of Se-Cys- or Se-Met-containing proteins/enzymes in the tissues of mammals (Collins 2017). The most important physiological functions of half of these Se-proteins/enzymes are to maintain the appropriate metabolism of $c 5 c 8 c 11 c 14 C 20: 4$, as well as low levels of free radicals or pre-oxides within cells, thus decreasing oxidative stress and peroxidative damage of UFA, DNA, cholesterol or sulphur-amino acids in proteins in the tissues of mammals (Choe and Min 2009, Čobanová et al. 2017, Czauderna et al. 2011, Saheem et al. 2017). In this context, special attention should be paid to the role of CA from Rosmarinus officinalis. CA is an abietane diterpenoid that is abieta-8,11,13-triene substituted by hydroxy groups at positions 11 and 12, and a carboxy group at position 20. Interestingly, CA exhibits neuroprotective, antiangiogenic, antineoplastic, antioxidant, antimicrobial and anti-HIV activity (Ibarra et al. 2011, Morán et al. 2012b, Jordán et al. 2013, Sasaki et al. 2013, Morán et al. 2017). What is more, CA added to diets has the ability to modify the microbial population in the rumen and, hence, the biosynthesis yields of volatile compounds, and UFA isomerisation and biohydrogenation in the rumen (Morán et al. 2012a, 2013, Miltko et al. 2016). Our current study and other studies have shown that CA added to diets with or without Se (as ${ }^{\mathrm{Y}} \mathrm{Se}$ or ${ }^{\mathrm{V}} \mathrm{Se}$ ) affected fatty acids profiles, the contents of cholesterol, its oxidation products and the accumulation of carbonyl moieties on proteins produced by oxidative stress in animal tissues (Ibarra et al. 2011, Morán et al. 2012a, Jordán et al. 2013, Rozbicka-Wieczorek et al. 2016a, 2016c). In accordance with the above, all experimental diets reduced the content of MDA, as well as the values of the PUFA peroxidation index in the PIF and SCF (Krajewska-Bienias et al. 2017), compared to the control diet.

\section{Impact of the experimental diets on the concentrations of fatty acids in the PIF}

Our results, summarised in Tables 4-6, showed that all experimental diets reduced the contents of even-long-chain SFA, c11C20:1, c9t11CLA, c11t14C20:2 and EPA in the PIF compared to the control, whereas the ${ }^{\mathrm{Y} S e-C A}$ and VISe-CA diets decreased the levels of $c 11 t 14 C 20: 2, c 5 c 8 c 11 c 14 C 20: 4$, EPA and DHA, as well as the value of the $\triangle 4$-desaturase index in the PIF in comparison with the control and CA diets. Based on the above results, it can be argued that ${ }^{Y} \mathrm{Se}$ or VISe added to the diet decreased the capacity of $\Delta 6$-, $\Delta 5$ - and especially $\Delta 4$-desaturase required for the biosynthesis of highly unsaturated LPUFA as EPA, DPA and DHA (bio-synthesised from $\alpha$ LNA), and $c 5 c 8 c 11 c 14 C 20: 4$ and $c 7 c 10 c 13 c 16 C 22: 4$ (biosynthesised from LA). This is consistent with the results of a previous study (Krajewska-Bienias et al. 2017), in which the ${ }^{\mathrm{Y} S}$ Se-CA and VISe-CA diets also reduced the contents of n-6LPUFA and n-3LPUFA in the SCF in comparison with the control diet. Moreover, in an earlier study conducted on lambs, it was also found that "Se added to a diet with linseed oil reduced the content of PUFA in the SCF and perirenal fat compared to a diet with linseed oil alone (Czauderna et al. 2012a).

As can be seen from the results summarised in Table 5, the experimental diets, especially the YSe-CA diet, fed to lambs resulted in an increase in the capacity of $\Delta 9$ desaturation in the PIF and SCF (Krajewska-Bienias et al. 2017) compared to the control diet. Considering the above, we suggested that dietary CA and particularly VISe added to the diet increased $\Delta 9$-desaturase capacity via stimulation of stearoyl-CoA desaturase mRNA expression in the PIF. Furthermore, the regulation of stearoyl-CoA desaturase activity is sensitive to diet composition, dietary supplements (like phenolic compounds, minerals or peroxisomal proliferators), as well as hormonal imbalances, 


\section{AGRICULTURAL AND FOOD SCIENCE}

M. Białek et al. (2020) 29: 405-419

developmental processes or temperature changes (Ntambi 1999). In addition, our results reinforce the finding that $\Delta 9$-desaturation capacity depends upon the chemical form of a substrate (Rozbicka-Wieczorek et al. 2014). In fact, the experimental diets, particularly those with ${ }^{\mathrm{Y} S e}$ or ${ }^{\mathrm{V}} \mathrm{Se}$, decreased the index of $\Delta 9$ desaturation of $t 11 \mathrm{C} 18: 1$ ( ${ }^{\mathrm{CLA}} \Delta$ 9-index) in the PIF compared to the control diet (Table 5); thus, the content of $c 9$ t11CLA (the product of $\Delta 9$ desaturase) was lower in the PIF (Table 6) and the SCF of lambs fed the experimental diets in comparison with the control diet (Krajewska-Bienias et al. 2017).

What is more, dietary ${ }^{Y}$ Se or VISe increased the capacity of enzymatic elongation of PUFA in the PIF; in fact, the PUFA elongase index was higher in the PIF of lambs fed the experimental diets with ${ }^{\mathrm{S} S e}$ or ${ }^{\mathrm{V}} \mathrm{Se}$ than the control and CA diets (Table 5). As a consequence, the content of $c 11 c 14 C 20: 2$ (the substrate for PUFA elongase) was considerably lower in the PIF, SCF (Krajewska-Bienias et al. 2017) and MBF (Table 8) of lambs fed the diets enriched in ${ }^{Y} \mathrm{Se}$ or VISe than the control and/or CA diets. In accordance with the above, the experimental diets, especially the 'Se-CA and V'Se-CA diets, considerably increased the contents of C21:0 and C23:0 (long-chain SFA). Considering the above, we suggested that CA added to the diet increased the capacity for the enzymatic elongation of odd-chain SFA (the substrates for elongase: C15:0, C17:0, C19:0 and C21:0) in the PIF compared to the control diet. Indeed, these enzymes are regulated/affected by dietary supplements, developmental processes, hormones and chronic diseases. As a consequence, changes in elongase activities impact fatty acid profiles in mammal tissues (Jump 2009). Moreover, YSe and especially VISe added to the experimental diet enhanced the capacity of odd-chain fatty acid elongases compared to the diet with only CA.

\section{Hypocholesterolemic/hypercholesterolemic FA ratio, and atherogenic and thrombogenic indices of lambs' tissues}

Our current and previous studies have suggested that the experimental diets containing CA with or without ${ }^{\mathrm{Y} S e}$ stimulated atherogenic properties in the PIF and SCF (Krajewska-Bienias et al. 2017). In fact, these experimental diets increased the concentration of A-SFA in the SCF, as well as the values of ${ }_{\text {index }} A^{\text {SFA }}$ in the PIF and SCF. Furthermore, atherogenesis, a multi-factor process, is stimulated by A-SFA (especially C14:0), and reduced by dietary n-3PUFA, as well as tocopherols (antioxidants). Recent studies have documented that diets enriched in tocopherols and plant oils rich in n-3PUFA have an antiatherogenic effect (i.e. reduced aortic cholesterol content, intimal lipid infiltration and discrete alterations to the middle layer of the arterial wall) (Saini et al. 2012, Haliga et al. 2015). In fact, "the oxidation theory" of antioxidant systems and atherosclerosis argues that oxidation of low density lipoproteins (LDL) significantly contributes to atherogenesis. Dietary antioxidants (i.e. tocopherols or tocotrienols) and coantioxidants (ascorbate and ubiquinol-10) prevent the oxidation of LDL, cholesterol and UFA in lipids, thus, delaying the atherogenesis process in animals and humans (Salvayre et al. 2016). Considering the above, we argued that the atherogenic index $\left(_{\text {index }} \mathrm{A}^{\mathrm{SFA}}\right)$ should be calculated based on the contents of pro-atherogenic saturated fatty acids (i.e. A-SFA), MUFA, n-6PUFA and n-3PUFA, as well as the contents of anti-atherogenic tocopherols in tissues. Thus, it seems reasonable to assume that the modified atherogenic index $\left({ }_{\text {index }} A^{\text {SFA+Toc }}\right)$ should be calculated in the following manner:

index $A^{\mathrm{SFA+Toc}}={ }_{\text {index }} \mathrm{A}^{\mathrm{SFA}} /\left(1.49 \times \mathrm{C}_{\alpha \mathrm{T}}+1.36 \times \mathrm{C}_{\alpha \mathrm{TAC}}+0.15 \times \mathrm{C}_{\gamma \mathrm{T}}+0.05 \times \mathrm{C}_{\delta \mathrm{T}}\right)$

where: $C_{\alpha \mathrm{T}}, C_{\alpha \mathrm{TAc}} \mathrm{C}_{\gamma \mathrm{T}}$ and $\mathrm{C}_{\delta \mathrm{T}}$ - the concentrations of $\alpha$-tocopherol, $\alpha$-tocopheryl acetate, $\gamma$-tocopherol and $\delta$-tocopherol respectively; $1.49,1.36,0.15$ and 0.05 are coefficients of the biological activity of tocopherols (Leth and Søndergaard 1977). In fact, all experimental diets, especially the YSe-CA diet, reduced the values of the modified atherogenic index index $A^{\mathrm{SFA}+\mathrm{Toc}}$ ) in the PIF, SCF and MLD compared to the control diet. Moreover, our current studies (Table 7) and previous investigations of cholesterol biosynthesis in the liver (Rozbicka-Wieczorek et al. 2016c) documented that ${ }^{\mathrm{V}} \mathrm{S}$ Se and/or CA added to the diet revealed anti-cholesterolemic activity.

Indeed, supplementation with "Se or especially with selenite reduced the activity of HMG-CoA reductase (3-hydroxy-3-methyl-glutaryl-coenzyme A reductase) (Nassir et al. 1997). This enzyme is the rate-controlling enzyme of the mevalonate pathway, the metabolic pathway that synthesizes cholesterol as well as other isoprenoids. Interestingly, HMG-CoA reductase possesses cysteine residues and is subject to regulation by thiol-disulfide exchange (Nassir et al. 1997). As a consequence, supplementation with CA (the effective antioxidant), "Se or particularly with selenite (Czauderna and Samochocka 1981) affects thiol-disulfide exchange equilibria and disulfide bond stability of HMG-CoA reductase. Moreover, the effect of dietary CA on cholesterol reduction may be attributed to a decrease in the micellar solubilisation of cholesterol in the digestive tract, to a stimulation in bile flow, bile cholesterol and bile acid content and to a subsequent increase in the faecal excretion of steroids 


\section{AGRICULTURAL AND FOOD SCIENCE}

M. Białek et al. (2020) 29: 405-419

(Ibarra et al. 2011, Afonso et al. 2013). Our current study and previous investigations suggest that dietary CA protects against hypercholesterolemia-induced oxidative stress, increasing the activities of antioxidant enzymes and decreasing the concentrations of reactive substances (Afonso et al. 2013, Jordán et al. 2013). Therefore, we argued that CA with or without Se (as ${ }^{\mathrm{V} S e}$ and VISe) reduced the concentrations of radicals (like ROS and RNS) in ovine tissues. As a consequence, the contents of MDA and the values of MDA $_{\text {index }}$ were lower in the PIF (Table 7) and SCF (Krajewska-Bienias et al. 2017) of lambs fed the experimental diets than the control diet. Moreover, we suggested that the experimental diets enriched in antioxidants reduced the oxidative degradation of tocopherols and stimulated the regeneration of degraded tocopherols in ovine tissues (Choe and Min 2009, Morán et al. 2012a, 2012b, 2017, Jordán et al. 2013, Haliga et al. 2015, Čobanová et al. 2017). In our opinion, compared with the atherogenic index $\left({ }_{\text {index }} A^{\text {SFA }}\right)$, the modified atherogenic index $\left({ }_{\text {index }} A^{\text {SFA+Toc }}\right.$ ) provides more detailed insights into the mechanisms of atherogenesis and, thus, possesses better predictive properties. Indeed, the effect of experimental diets enriched in antioxidant(s) on the values of ${ }_{\text {index }} A^{\mathrm{SFA}+\mathrm{Toc}}$ is more consistent than on the values of ${ }_{\text {index }} \mathrm{A}^{\mathrm{SFA}}$ in all assayed tissues. The values of our modified atherogenic index $\left({ }_{\text {index }} A^{\text {SFA+Toc }}\right.$ ) confirmed that the experimental diets including antioxidants (i.e. CA, 'VISe and especially ${ }^{\text {YSe) }}$ reduced the risk of atherogenesis (Saini et al. 2012, Salvayre et al. 2016).

In this and earlier studies, we have confirmed that the CA and 'Se-CA diets reduced the thrombogenic properties in the PIF, SCF (Krajewska-Bienias et al. 2017), the rumen-surrounding fat (Białek and Czauderna 2019) and

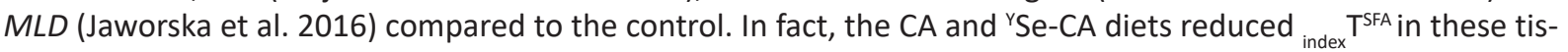
sues more efficiently than the control diet. Similarly, compared with the control diet, the VISe-CA diet decreased index $^{\text {SFA }}$ or T-SFA in the PIF, SCF and MLD, as its values were lower than in the control tissues. Our current and our recent studies have also showed that the experimental diet with ${ }^{V}$ Se increased the $\sum$ PUFA/ $\sum$ SFA ratio in the PIF, $M L D$ and $M B F$, as well as the $\mathrm{h} / \mathrm{H}-\mathrm{Ch}$ ratio in the PIF, SCF, MLD and MBF of lambs compared to the control. Considering the above, we argued that the experimental diets, especially the 'Se-CA diet, improved the health and welfare of lambs (which probably applies to other ruminants), as well as the nutritional value of lambs' meat (i.e. $M L D$ and $M B F$ ) and the SCF for humans. Indeed, the high $\sum$ PUFA/ $\sum S F A$ and $\mathrm{h} / \mathrm{H}-\mathrm{Ch}$ ratios and the low values of atherogenic and thrombogenic indices in MLD and MBF (Jaworska et al. 2016, Rozbicka-Wieczorek et al. 2016b) documented their suitability for healthier diets, since these diets are successful in slowing down the atherosclerosis and thrombogenesis processes. As a consequence, the meat of lambs fed the ${ }^{\mathrm{V} S e-C A}$ diet in particular may decrease the threat of atrial fibrillation, coronary thrombosis and the risk of cardiovascular disorders in humans (Fernández et al. 2007, Haliga et al. 2015, Salvayre et al. 2016).

\section{Conclusion}

The current study is important for the understanding of the influence of dietary CA, "Se and VISe on the contents of FA, cholesterol and tocopherols in the adipose tissues and muscles of lambs. Alongside earlier studies performed on ruminal microbiota, the present research confirmed that dietary ${ }^{\mathrm{V} S e}$ and ${ }^{\mathrm{V}} \mathrm{Se}$, as well as CA, have the ability to modify the metabolism of FA in ruminal microorganisms, adipose tissues and muscles of lambs. Our data indicated that dietary CA combines antioxidant and hypocholesterolemic activities. The modified atherogenic index strongly suggests that the experimental diets containing CA, irrespective of the presence of ${ }^{\gamma} \mathrm{Se}$ or ${ }^{\mathrm{V}} \mathrm{Se}$, decreased the atherogenic capacity of the PIF, SCF, MLD and MBF compared to the control diet. In our opinion, the modified atherogenic index ${ }_{\text {index }} A^{\mathrm{SFA}+T o c}$ ) better assesses the atherogenic capacity of tissues, as it takes into consideration the contents of pro-atherogenic SFA, as well as the contents of anti-atherogenic tocopherols in the analysed tissues. Therefore, we argued that the modified atherogenic index is a better assessment tool for the atherogenic properties of tissues than the commonly used atherogenic index $\left({ }_{\text {index }} \mathrm{AFA}^{\mathrm{SF}}\right)$. Our studies have shown that the PIF, $M L D$ and $M B F$ of lambs fed the VISe-CA diet were characterised by the highest $\Sigma$ PUFA/ $\Sigma$ SFA and hypocholesterolemic/hypercholesterolemic FA ratios, as well as lower atherogenic and thrombogenic indices and contents of TCh and MDA compared to the control and other experimental diets. Therefore, we argued that the experimental diet with CA and 'Se in particular, improved lambs' health and welfare, as well as the dietary properties of animal products for human consumption.

Further studies are necessary to determine if diets containing CA and Se (as ${ }^{\mathrm{V} S e}$ or ${ }^{\mathrm{V}} \mathrm{S} \mathrm{Se}$ ) along with FO and RO induce changes in the content of FA, tocopherols, cholesterol and MDA in the perirenal fat of lambs. Moreover, new studies are necessary to determine if dietary supplementations with Se (as Y Se or V'Se) and carnosol (the oxidation product of CA) affect the bioaccumulations of FA (especially n-3LPUFA and conjugated PUFA), tocopherols, tocotrienols and peroxidation products of cholesterol and steroid hormones in adipose tissues, muscles and, in particular, in the liver, brain and heart of lambs. The current studies also provides useful knowledge for nutritionists carrying out further studies aimed at improving the health and welfare of farm animals, as well as the prohealthy properties of animal products for human consumption. 


\section{Acknowledgments}

This study was in part supported by the National Science Centre (Grant No. 2013/09/B/NZ9/00291) and by the statutory funds from The Kielanowski Institute of Animal Physiology and Nutrition, PAS (Poland).

\section{References}

Afonso, M.S., de O Silva, A.M., Carvalho, E.B.T., Rivelli, D.P., Barros, S.B.M., Rogero, M.M., Lottenberg, A.M., Torres, R.P. \& ManciniFilho, J. 2013. Phenolic compounds from Rosemary (Rosmarinus officinalis L.) attenuate oxidative stress and reduce blood cholesterol concentrations in diet-induced hypercholesterolemic rats. Nutrition \& Metabolism 10: 19. https://doi.org/10.1186/17437075-10-19

Białek, M., Czauderna, M. \& Białek, A. 2018. Partial replacement of rapeseed oil with fish oil, and dietary antioxidants supplementation affects concentrations of biohydrogenation products and conjugated fatty acids in rumen and selected lamb tissues. Animal Feed Science and Technology 241: 64-74. https://doi.org/10.1016/j.anifeedsci.2018.04.015

Białek, M. \& Czauderna, M. 2019. Composition of rumen-surrounding fat and fatty acid profile in selected tissues of lambs fed diets supplemented with fish and rapeseed oils, carnosic acid, and different chemical forms of selenium. Livestock Science 226 : 122-132. https://doi.org/10.1016/j.livsci.2019.06.013

Białek, M., Czauderna, M., Przybylski, W. \& Jaworska, D. 2020. Selenate and selenite affect ruminal metabolism of C18 unsaturated fatty acids and fatty acid composition of lamb tissues. Livestock Science 241:104249. https://doi.org/10.1016/j.livsci.2020.104249

Choe, E. \& Min, D.B. 2009. Mechanisms of antioxidants in the oxidation of foods. Comprehensive Reviews in Food Science and Food Safety 8: 345-358. https://doi.org/10.1111/j.1541-4337.2009.00085.x

Čobanová, K., Faix, S., Plachá, I., Mihaliková, K., Váradyová, Z., Kišidayová, S. \& Grešáková, L. 2017. Effects of different dietary selenium sources on antioxidant status and blood phagocytic activity in sheep. Biological Trace Element Research 175: 339-346. https://doi.org/10.1007/s12011-016-0794-0

Cobellis, G., Yu, Z., Forte, C., Acuti, G. \& Trabalza-Marinucci, M. 2016. Dietary supplementation of Rosmarinus officinalis L. leaves in sheep affects the abundance of rumen methanogens and other microbial populations. Journal of Animal Science and Biotechnology 7: 27. https://doi.org/10.1186/s40104-016-0086-8

Collins, J.F. 2017. Molecular, genetic, and nutritional aspects of major and trace minerals. Academic Press is an imprint of Elsevier, Amsterdam • Boston • Heidelberg • London • New York • OXFORD • Paris • San Diego • San Francisco • Singapore • Sydney • Tokyo, 2017. $576 \mathrm{p}$

Czauderna, M., Białek, M., Krajewska, K.A., Ruszczyńska, A. \& Bulska, E. 2017. Selenium supplementation into diets containing carnosic acid, fish and rapeseed oils affects the chemical profile of whole blood in lambs. Journal of Animal and Feed Sciences 26: 192-203. https://doi.org/10.22358/jafs/76594/2017

Czauderna, M., Kowalczyk, J., Korniluk, K. \& Wąsowska, I. 2007. Improved saponification then mild base and acid-catalyzed methylation is a useful method for quantifying fatty acids, with special emphasis on conjugated dienes. Acta Chromatographica 18: 59-71.

Czauderna, M., Kowalczyk, J. \& Marounek, M. 2011. The simple and sensitive measurement of malondialdehyde in selected specimens of biological origin and some feed by reversed phase high performance liquid chromatography. Journal of Chromatography B 879: 2251-2258. https://doi.org/10.1016/j.jchromb.2011.06.008

Czauderna, M., Kowalczyk, J. \& Marounek, M. 2012a. Dietary linseed oil and selenate affect the concentration of fatty acids in selected tissues of sheep. Czech Journal of Animal Science 57: 389-401. https://doi.org/10.17221/6313-CJAS

Czauderna, M., Kowalczyk, J. \& Niedźwiedzka, K.M. 2009a. Simple HPLC analysis of tocopherols and cholesterol from specimens of animal origin. Chemia Analityczna (Warsaw) 54: 203-214.

Czauderna, M., Kowalczyk, J., Niedźwiedzka, K.M., Leng, L. \& Cobanova, K. 2009b. Dietary selenized yeast and CLA isomer mixture affect fatty- and amino acid concentrations in the femoral muscles and liver of rats. Journal Animal and Feed Sciences 18: 348-361. https://doi.org/10.22358/jafs/66399/2009

Czauderna, M., Kowalczyk, J. \& Wallace, J.R. 2012b Selenite and selenate affected the fatty acid profile in in vitro incubated ovine ruminal fluid containing linoleic acid. Journal of Animal and Feed Sciences 21: 477-492. https://doi.org/10.22358/jafs/66121/2012

Czauderna, M., Rozbicka-Wieczorek, A.J. \& Więsyk, E. 2014. Seleno-cystine affects the fatty acid profile in in vitro incubated ovine ruminal fluid containing $\alpha$-linolenic acid. Animal Review 1: 45-56. http://www.pakinsight.com/?ic=journal\&journal=92.

Czauderna, M., Rozbicka-Wieczorek, A.J., Wiesyk, E. \& Krajewska-Bienias, K.A. 2015. Seleno-methionine decreases biohydrogenation of C18 unsaturated fatty acids in ovine ruminal fluid incubated in vitro with $\alpha$-linolenic acid. European Journal of Lipid Science and Technology 117: 820-829. https://doi.org/10.1002/ejlt.201400476

Czauderna, M., Ruszczyńska, A., Bulska, A. \& Krajewska, K.A. 2018. Seleno-compounds and carnosic acid added to diets with rapeseed and fish oils affect concentrations of selected elements and chemical composition in the liver, heart and muscles of lambs. Biological Trace Element Research 184: 378-390. https://doi.org/10.1007/s12011-017-1211-z

Czauderna, M. \& Samochocka, K. 1981. Se-incorporation into sulfur amino acids and GSH and the stability of the incorporation products. Journal of Labelled Compounds and Radiopharmaceuticals 8: 829-854. https://doi.org/10.1002/jlcr.2580180610

Edens, F.W. \& Sefton, A.E. 2016. Organic selenium in animal nutrition - utilisation, metabolism, storage and comparison with other selenium sources. Journal of Applied Animal Nutrition 4: 1-14. https://doi.org/10.1017/jan.2016.5

El-Ramady, H., Abdalla, N., Alshaal, T., Domokos-Szabolcsy, É., Elhawat, N., Prokisch, J., Sztrik, A., Fári, M., El-Marsafawy, S. \& Shams, M.S. 2015. Selenium in soils under climate change, implication for human health. A review. Environmental Chemistry Letters 13: 1-19. https://doi.org/10.1007/s10311-015-0535-1. 
Eun, J.S., Davis, T.Z., Vera, J.M., Miller, D.N., Panter, K.E. \& ZoBell, D.R. 2013. Addition of high concentration of inorganic selenium in orchardgrass (Dactylis glomerata L.) hay diet does not interfere with microbial fermentation in mixed ruminal microorganisms in continuous cultures. The Professional Animal Scientist 29: 39-45. https://doi.org/10.15232/S1080-7446(15)30193-5

Fernández, M., Ordóňez, J.A., Cambero, I., Santos, C., Pin, C. \& de la Hoz, L. 2007. Fatty acid compositions of selected varieties of Spanish dry ham related to their nutritional implications. Food Chemistry 101: 107-112. https://doi.org/10.1016/j.foodchem.2006.01.006

Gargiulo, S., Testa, G., Gamba, P., Staurenghi, E., Poli, G. \& Leonarduzzi, G. 2017. Oxysterols and 4-hydroxy-2-nonenal contribute to atherosclerotic plaque destabilization. Free Radical Biology and Medicine 111: 140-150. https://doi.org/10.1016/j.freeradbiomed.2016.12.037

Hadad, N. \& Levy, R. 2012. The synergistic anti-inflammatory effects of lycopene, lutein, b-carotene, and carnosic acid combinations via redox-based inhibition of NF-kB signaling. Free Radical Biology and Medicine 53: 1381-1391. https://doi.org/10.1016/j.freeradbiomed.2012.07.078

Haliga, R.E., Mocanu, V. \& Badescu, M. 2015. Antioxidative and antiatherogenic effects of flaxseed, atocopherol and their combination in diabetic hamsters fed with a highfat diet. Experimental and Therapeutic Medicine 9: 533-538. https://doi.org/10.3892/etm.2014.2102

Ibarra, A., Cases, J., Roller, M., Chiralt-Boix, A., Coussaert, A. \& Ripoll, C. 2011. Carnosic acid rich rosemary (Rosmarinus officinalis L.) leaf extract limits weight gain and improves cholesterol levels and glycaemia in mice on a high-fat diet. British Journal of Nutrition 106: 1182-1118. https://doi.org/10.1017/S0007114511001620

Jaworska, D., Czauderna, M., Przybylski, W. \& Rozbicka-Wieczorek, A.J. 2016. Sensory quality and chemical composition of meat from lambs fed diets enriched with fish and rapeseed oils, carnosic acid and seleno-compounds. Meat Science 119: $185-192$. https://doi.org/10.1016/j.meatsci.2016.05.003

Jordán, M.J., Lax, V., Rota, M.C., Loran, S. \& Sotomayor, J.A. 2013. Effect of the phenological stage on the chemical composition, and antimicrobial and antioxidant properties of Rosmarinus z essential oil and its polyphenolic extract. Industrial Crops and Products 48: 144-152. https://doi.org/10.1016/j.indcrop.2013.04.031

Johnson, J.J. 2011. Carnosol: A promising anti-cancer and anti-inflammatory agent. Cancer Letter 305: 1-7. https://doi.org/10.1016/j.canlet.2011.02.005

Jump, D.B. 2009. Mammalian fatty acid elongases. Methods in Molecular Biology 579: 375-389.

https://doi.org/10.1007/978-1-60761-322-0_19

Juszczuk-Kubiak, E., Bujko, K., Cymer, M., Wicińska, K., Gabryszuk, M. \& Pierzchała, M. 2016. Effect of inorganic dietary selenium supplementation on selenoprotein and lipid metabolism gene expression patterns in liver and loin muscle of growing lambs. Biological Trace Element Research 172: 336-345. https://doi.org/10.1007/s12011-015-0592-0

Krajewska-Bienias, K.A., Czauderna, M., Marounek, M. \& Rozbicka-Wieczorek, A.J. 2017. Diets containing selenized yeast, selenate carnosic acid and fish oil change the content of fatty acids, tocopherols and cholesterol in the subcutaneous fat of lambs. Journal of Animal and Plant Sciences 27: 1781-1794.

Kišidayová, S., Mihaliková, K., Siroka, P., Čobanová, K. \& Váradyová, Z. 2014. Effects of inorganic and organic selenium on the fatty acid composition of rumen contents of sheep and the rumen bacteria and ciliated protozoa. Animal Feed Science and Technology 193: 51-57. https://doi.org/10.1016/j.anifeedsci.2014.04.008

Leth, T. \& Søndergaard, H. 1977. Biological activity of vitamin e compounds and natural materials by the resorption-gestation test, and chemical determination of the vitamin e activity in foods and feeds. Journal of Nutrition 107: 2236-2243. https://doi.org/10.1093/jn/107.12.2236

Masuda, T., Inaba, Y. \& Takeda, Y. 2001. Antioxidant mechanism of carnosic acid: structural identification of two oxidation products. Journal of Agricultural and Food Chemistry 49: 5560-5565. https://doi.org/10.1021/jf010693i

Miltko, R., Rozbicka-Wieczorek, J.A., Wiesyk, E. \& Czauderna, M. 2016. The influence of different chemical forms of selenium added to the diet including carnosic acid, fish oil and rapeseed oil on the formation of volatile fatty acids and methane in rumen and fatty acid profiles in the rumen content and muscles of lambs. Acta Veterinaria (Beograd) 66: 373-391. https://doi.org/10.1515/acve-2016-0032

Morán, L., Andres, S., Bodas, R., Benavides, J., Prieto, N., Perez, V. \& Giraldez, F.J. 2012a. Antioxidants included in the diet of fattening lambs: effects on immune response, stress, welfare and distal gut microbiota. Animal Feed Science and Technology 173: 177-185. https://doi.org/10.1016/j.anifeedsci.2012.01.010

Morán, L., Andrés, S., Bodas, R., Prieto, N. \& Giráldez, F.J. 2012b. Meat texture and antioxidant status are improved when carnosic acid is included in the diet of fattening lambs. Meat Science 91: 430-434. https://doi.org/10.1016/j.meatsci.2012.02.027

Morán, L., Giráldez, F.J., Panseri, S., Aldai, N., Jordán, M.J., Chiesa, L.M. \& Andrés, S. 2013. Effect of dietary carnosic acid on the fatty acid profile and flavour stability of meat from fattening lambs. Food Chemistry 138: 2407-2414.

https://doi.org/10.1016/j.foodchem.2012.12.033

Morán, L., Andrés, S., Blanco, C., Benavides, J., Martínez-Valladares, M., Moloney, A.P. \& Giráldez, F.J. 2017. Effect of dietary supplementation with carnosic acid or vitamin $\mathrm{E}$ on animal performance, haematological and immunological characteristics of artificially reared suckling lambs before and after road transport. Archives of Animal Nutrition 71: 272-284. https://doi.org/10.1080/1745039X.2017.1316137

Nassir, F., Moundras, C., Bayle, D., Serougne, C., Gueux, E., Rock, E., Rayssiguier, Y. \& Mazur, A. 1997. Effect of selenium deficiency on hepatic lipid and lipoprotein metabolism in the rat. British Journal of Nutrition 78: 493-500. https://doi.org/10.1079/BJN19970166

Navarro-Alarcon, M. \& Cabrera-Vique, C. 2008. Selenium in food and the human body: A review. Sci. Total. Environ. 400: 115-141. https://doi.org/10.1016/j.scitotenv.2008.06.024

NRC 2007. Nutrient Requirements of Small Ruminants: Sheep, Goats, Cervids, and New World Camelids. Washington, DC, USA: The National Academies Press. p. 384. 
Ntambi, J.M. 1999. Regulation of stearoyl-CoA desaturase by polyunsaturated fatty acids and cholesterol. Journal of Lipid Research 40: 1549-1558.

Ortuño, J., Serrano, R. \& Bañón, S. 2017. Incorporating rosemary diterpenes in lamb diet to improve microbial quality of meat packed in different environments. Animal Science Journal 88: 1436-1445. https://doi.org/10.1111/asj.12768

Ošt'ádalová, I. 2012. Biological effects of selenium compounds with a particular attention to the ontogenetic development. Physiological Research 61(Suppl. 1): S19-S23. https://doi.org/10.33549/physiolres.932327

Przybylski, W., Żelechowska, E., Czauderna, M., Jaworska, D., Kalicka, K. \& Wereszka, K. 2017. Protein profile and physicochemical characteristics of meat of lambs fed diets supplemented with rapeseed oil, fish oil, carnosic acid, and different chemical forms of selenium. Archives Animal Breeding 60: 105-118. https://doi.org/10.5194/aab-60-105-2017

Raman, M.P. 2000. The importance of selenium to human health. Lancet 356: 233-241. https://doi.org/10.1016/S0140-6736(00)02490-9

Romero-Pérez, A., García-García, E., Zavaleta-Mancera, A., Ramírez-Bribiesca, J.E., Revilla-Vázquez, A., Hernández-Calva, L.M. López-Arellano, R. \& Cruz-Monterrosa, R.G. 2010. Designing and evaluation of sodium selenite nanoparticles in vitro to improve selenium absorption in ruminants. Veterinary Research Communications 34: 71-79. https://doi.org/10.1007/s11259-009-9335-z

Rozbicka-Wieczorek, A.J., Więsyk, E., Brzóska, F., Śliwiński, B., Kowalczyk, J. \& Czauderna, M. 2014. Efficiency of fatty acid accumulation into breast muscles of chickens fed diets with lycopene, fish oil and different chemical selenium forms. African Journal of Biotechnology 13: 1604-1613.

Rozbicka-Wieczorek, J.A., Krajewska-Bienias, K.A. \& Czauderna, M. 2016a. Dietary carnosic acid, selenized yeast, selenate and fish oil affected the concentration of fatty acids, tocopherols, cholesterol and aldehydes in the brains of lambs. Archives Animal Breeding 59: 215-226. https://doi.org/10.5194/aab-59-215-2016

Rozbicka-Wieczorek, A.J., Więsyk, E., Czauderna, M. \& Radzik-Rant, A. 2016b. Dietary carnosic acid, selenized yeast or selenate affect the concentration of fatty acids in muscles of lambs. Journal of Animal and Feed Sciences 25: $216-225$. https://doi.org/10.22358/jafs/65555/2016

Rozbicka-Wieczorek, A.J., Wiesyk, E., Krajewska-Bienias, K.A., Wereszka, K. \& Czauderna, M. 2016c. Supplementation effects of seleno-compounds, carnosic acid, and fish oil on concentrations of fatty acids, tocopherols, cholesterol, and amino acids in the livers of lambs. Turkish Journal of Veterinary and Animal Sciences 40: 681-693. https://doi.org/10.3906/vet-1509-12

Saheem, A., Hamda, K., Uzma, S., Shahnawaz, R., Zeeshan, R., Mohd, Y.K., Ahsanullah, A., Zeba, S., Jalaluddin, M.A., Saleh, M.S.A., Safia, H. \& Moin, U. 2017. Protein oxidation: an overview of metabolism of sulphur containing amino acid, cysteine. Frontiers in Bioscience 9: 71-87. https://doi.org/10.2741/s474

Saini, V., Fatima, N., Ishaq, S.B.F., Singh, R.N. \& Khan, A. 2012. Anti-atherogenic and anti-oxidant effect of tocopherol and tocotrienols on $\mathrm{Cu}++$ mediated low-density lipoprotein (LDL) oxidation in normallipidemic subjects. European Journal of Experimental Biology 2: 1071-1086.

Salvayre, R., Negre-Salvayre, A. \& Camaré, C. 2016. Oxidative theory of atherosclerosis and antioxidants. Biochimie 125: 281-296. https://doi.org/10.1016/j.biochi.2015.12.014

Sasaki, K., El Omri, A., Kondo, S., Han, J. \& Isoda, H. 2013. Rosmarinus officinalis polyphenols produce anti-depressant like effect through monoaminergic and cholinergic functions modulation. Behavioural Brain Research 238: 86-94. https://doi.org/10.1016/j.bbr.2012.10.010

Van Dael, P., Davidsson, L., Muñoz-Box, R., Fay, L.B. \& Barclay, D. 2001. Selenium absorption and retention from a selenite- or selenate-fortified milk-based formula in men measured by a stable-isotope technique. British Journal of Nutrition 85: $157-163$. https://doi.org/10.1079/BJN2000227

Zhao, Z., Barcus, M., Kim, J., Lum, K.L., Mills, C. \& Lei, X.G. 2016. High dietary selenium intake alters lipid metabolism and protein synthesis in liver and muscle of pigs. Journal of Nutrition 146: 1625-1633. https://doi.org/10.3945/jn.116.229955 